\title{
Identification of prohormones and pituitary neuropeptides in the African cichlid, Astatotilapia burtoni
}

Caroline K. Hu ${ }^{1,5}$, Bruce R. Southey ${ }^{2}$, Elena V. Romanova ${ }^{3}$, Karen P. Maruska ${ }^{4}$, Jonathan V. Sweedler ${ }^{3}$ and Russell D. Fernald ${ }^{1 *}$

\begin{abstract}
Background: Cichlid fishes have evolved remarkably diverse reproductive, social, and feeding behaviors. Cell-to-cell signaling molecules, notably neuropeptides and peptide hormones, are known to regulate these behaviors across vertebrates. This class of signaling molecules derives from prohormone genes that have undergone multiple duplications and losses in fishes. Whether and how subfunctionalization, neofunctionalization, or losses of neuropeptides and peptide hormones have contributed to fish behavioral diversity is largely unknown. Information on fish prohormones has been limited and is complicated by the whole genome duplication of the teleost ancestor. We combined bioinformatics, mass spectrometry-enabled peptidomics, and molecular techniques to identify the suite of neuropeptide prohormones and pituitary peptide products in Astatotilapia burtoni, a well-studied member of the diverse African cichlid clade.
\end{abstract}

Results: Utilizing the A. burtoni genome, we identified 148 prohormone genes, with 21 identified as a single copy and 39 with at least 2 duplicated copies. Retention of prohormone duplicates was therefore $41 \%$, which is markedly above previous reports for the genome-wide average in teleosts. Beyond the expected whole genome duplication, differences between cichlids and mammals can be attributed to gene loss in tetrapods and additional duplication after divergence. Mass spectrometric analysis of the pituitary identified 620 unique peptide sequences that were matched to 120 unique proteins. Finally, we used in situ hybridization to localize the expression of galanin, a prohormone with exceptional sequence divergence in cichlids, as well as the expression of a proopiomelanocortin, prohormone that has undergone an additional duplication in some bony fish lineages.

Conclusion: We characterized the A. burtoni prohormone complement. Two thirds of prohormone families contain duplications either from the teleost whole genome duplication or a more recent duplication. Our bioinformatic and mass spectrometric findings provide information on a major vertebrate clade that will further our understanding of the functional ramifications of these prohormone losses, duplications, and sequence changes across vertebrate evolution. In the context of the cichlid radiation, these findings will also facilitate the exploration of neuropeptide and peptide hormone function in behavioral diversity both within A. burtoni and across cichlid and other fish species.

Keywords: Prohormone, Neuropeptide, Cichlid, Astatotilapia burtoni, Mass spectrometry

\footnotetext{
* Correspondence: rfernald@stanford.edu

'Department of Biology, Stanford University, Stanford, CA 94305, USA

Full list of author information is available at the end of the article
} 


\section{Background}

Ray-finned fishes comprise $\sim 50 \%$ of all vertebrate species and of these, teleost fishes are the most diverse clade. They are found in most aquatic habitats and exhibit vast behavioral differences between species. Among teleost fishes, cichlids are one of the most species-rich families and the African cichlids, in particular, provide exceptional and unique opportunities for understanding speciation and behavioral adaptations in the African Great Lakes [1]. Cichlid phenotypic diversity in behavior, body shape, coloration, and ecological specialization is unparalleled. Some substrates for cichlid morphological diversity include well-conserved morphogen systems, and potentially the Hox gene clusters [2-4]. Although cichlid behavioral diversity has encouraged behavioral and neurobiological studies directed at understanding how brain evolution has been shaped by natural and sexual selection, the molecular and cellular bases of teleost/cichlid behavioral diversity are still largely unknown. This status is poised to change. Not only have analyses shown remarkable social and cognitive skills associated with cichlid group living [5], the recent sequencing of five cichlid genomes [6] and the development of cichlid transgenesis techniques $[7,8]$ have opened the door to greater understanding of the underlying mechanisms.

It has been speculated that the rich diversity and complexity of behaviors found in teleosts partially derives from a whole genome duplication (WGD) in the teleost ancestor after the divergence from other vertebrate lineages $[9,10]$. Approximately $85 \%$ of genes resulting from this duplication were subsequently lost, but amongst the retained duplicates, genes associated with brain function are overrepresented $[9,11]$. Retained duplicated genes can be a source of novel gene function as they frequently undergo subfunctionalization, neofunctionalization, or some combination of the two [12]. In the haplochromine cichlid lineage, for example, neofunctionalization of a paralog has been linked to the morphological innovation of male fin spots involved in mating behavior [13].

Neuropeptides play a pivotal role in both ancient and recently derived examples of animal behavior. For example, the galanin peptide is functionally associated with the regulation of feeding, anxiety-related behaviors, and parental behavior in mammals [14, 15]. Galanin's orexigenic function has been described in teleosts, but whether it serves additional neuroendocrine or behavioral functions is unknown [16]. In Astatotilapia burtoni, whole brain galanin $(G A L)$ expression is higher in socially dominant males compared to socially subordinate males [17]. Duplication of prohormone genes such as proopiomelanocortin $(P O M C)$ that encode multiple neuropeptides may similarly be a source of behavioral innovation through change in expression and sequence. Teleosts possess duplicate POMC genes and A. burtoni, as well as several other teleost lineages, have undergone a more recent $P O M C 1$ duplication to generate $P O M C 1 A$ and $P O M C 1 B$ [18]. Many POMC peptide products, including melanocortins and $\beta$-endorphin, exert pleiotropic functions in multiple tissues, including the nervous system, reproductive system, and skin. Thus, regulation of $P O M C$ is a possible mechanistic link between behavior, physiology, and coloration within and across species [19]. Identification of which $P O M C$ versions are being expressed and which peptides are present is essential to understanding this link.

This effort to characterize the prohormone gene and novel neuropeptide complement for $A$. burtoni is the first comprehensive bioinformatic survey of any single ray-finned fish species. A. burtoni is a haplochromine cichlid with an advantageous phylogenetic position and a well-characterized natural history [20], and has undergone extensive physiological, neurobiological, and molecular analyses [21]. Molecular phylogenetics place this species in a sister group to the extremely large cichlid species flocks in Lakes Victoria and Malawi in East Africa. A. burtoni is hypothesized to be similar to the ancestor of these flocks because it is a trophic generalist endemic to the neighboring Lake Tanganyika and surrounding rivers [22, 23]. Thus, discoveries about the peptidome of $A$. burtoni are significant to the entire 'modern haplochromine' lineage, which represents $\sim 7 \%$ of all extant teleosts.

\section{Results and discussion}

We surveyed the A. burtoni genome for prohormone genes as well as the major processing enzymes used to form bioactive peptides from the prohormone proteins. While previous studies have only examined individual prohormones and specific prohormone families, our study provides a comprehensive summary of all known prohormones. As the final bioactive complement requires the prohormone and appropriate processing enzymes, we also characterized the peptides themselves within the endocrine pituitary using mass spectrometry (MS). Finally, in situ hybridization was used to localize the expression of 2 prohormones, GAL and POMC.

Our survey identified 158 A. burtoni genes, with 148 prohormone genes and 10 prohormone convertase subtilisin/kexin (PCSK) genes. All prohormone genes, including current accession numbers and genomic locations [6], are provided in Additional file 1: Table S1. All predicted sequences can be found in FASTA format in Additional file 2: Text S1, which also includes 7 genes with 2 splice variants and 1 gene with 3 splice variants. All predictions except glucagon II (GCG2), kisspeptin-2 (KISS2), neuropeptide VF precursor (NPVF), prokineticin 2 (PROK2) and parathyroid hormone A (PTHA) were supported by $A$. burtoni expressed sequence tag (EST) data. Predictions without A. burtoni EST data were all supported by Oreochromis niloticus (Nile tilapia) EST data. Gastrin-releasing peptide 
$(G R P)$ was not identified in the assembly but was identified from A. burtoni and O. niloticus EST data.

The 148 prohormone genes consisted of 6 genes that were only identified in fish, 21 genes identified with a single copy, and 39 genes with at least 2 duplicated copies (Table 1). Compared to the average rate of gene retention following the teleost WGD of $15 \%[9,11]$, we found prohormone genes to be retained at $41 \%$ (39 genes with multiple copies out of 96 unique prohormone genes). Almost $66 \%$ of the currently identified prohormone families contained at least one gene duplication (23 out of 35 families) (Table 1). The 6 predictions lacking direct mammalian counterparts are likely due to either gene loss in tetrapods or additional duplication after divergence of cichlid and mammals.

\section{Gonadotropin-releasing hormone and oxytocin/ vasopressin families}

The gonadotropin-releasing hormone $(G N R H)$ and oxytocin/vasopressin families comprise the most functionally well-characterized prohormones in A. burtoni [24, 25]. Our genomic survey confirms previous findings of single copies of three GNRH genes (GNRH1, GNRH2, and GNRH3), as well as single copies of oxytocin (OXT) and arginine vasopressin $(A V P)$. In Oryzias latipes (Japanese medaka fish), GnRH3 peptide is produced in the terminal nerve ganglion and modulates social behavior [26]. It is unknown whether this neuromodulatory role is shared across teleosts and whether this role is fulfilled by GnRH1 in tetrapods, which lack GNRH3 [27, 28]. Evidence based on the receptors suggests that GNRH, OXT, AVP and neuropeptide $\mathrm{S}$ (NPS) genes share a common ancestor $[29,30]$. Analysis of Branchiostoma floridae (lancelet) $A V P, G N R H$, and NPS prohormones indicate conserved synteny of these prohormones [31]. It is theorized that the NPS system was lost in ray-finned fish after the duplication of an ancestral system that resulted in the OXT/AVP system and the NPS system [30]. Consistent with this hypothesis, there was no evidence of NPS in A. burtoni.

\section{Insulin and relaxin families}

Duplicate copies of insulin (INS1 and INS2) and single copies of insulin-like growth factors 1 (IGF1), 2 (IGF2), and 3 (IGF3) were identified. IGF3 is a teleost-specific, gonad-specific prohormone [32]. Following Wilkinson et al. [33] and Yegorov and Good [34], 2 copies of relaxin 3 (RLN3A and RLN3B) and insulin-like 5 (INSL5A and INSL $5 B$ ) and single copies of relaxin 1 (RLN1) and insulin-like 3 (INSL3) were also identified. Multiple sequence alignment indicated that INS1, INS2, IGF1, and IGF2 were more similar to the mammalian counterparts than other members of the relaxin family. Similar to Yegorov and Good [34], only the 2 copies of $A$. burtoni RLN3 showed more similarity to the Homo sapiens (human) relaxin family counterparts than the other identified genes. The other 3 relaxin members had intermediate similarity between the H. sapiens RLN3 and the other $H$. sapiens relaxin family members.

\section{Glucagon family}

Searching the A. burtoni genome identified 6 of the 7 known members of the glucagon family: 2 glucagon 1 (GCG1) copies (GCG1A and GCG1B), 2 adenylate cyclase activating polypeptide 1 copies (ADCYAP1A and $A D C Y A P 1 B)$, and single copies of glucagon 2 (GCG2), gastric inhibitory polypeptide $(G I P)$, growth hormone releasing hormone $(G H R H)$, and vasoactive intestinal peptide $(V I P)$. All identified prohormones were more similar in sequence to their respective $H$. sapiens and Gallus gallus (chicken) homologues than the other glucagon members. GCG2 is similar to glucagon type II found in O. latipes, G. gallus, and Xenopus (Silurana) tropicalis (western clawed frog) [35, 36]. This second glucagon has been lost in mammals since there are no detectable sequences or conserved synteny found in mammalian genomes [35]. No secretin (SCT) was identified in $A$. burtoni, as it is considered lost in teleosts, but the $S C T$ receptor has been identified [37, 38].

\section{Somatostatin and urotensin II families}

Following Tostivint et al. [39, 40], single copies of 4 members of the somatostatin (SST) family were identified (SST1, SST2, SST3, and SST5) in A. burtoni, but no evidence of other SST versions. It is proposed that the somatostatin and urotensin II families are related by an early evolutionary event [39-43]. The urotensin II family consists of 2 members, urotensin 2 (UTS2) and urotensin $2 \mathrm{~B}$ (UTS2B), that are widespread through many taxa including invertebrates [44]. In addition, the urotensin II family consists of two additional members, urotensin II-related peptide 1 (URP1) and urotensin II-related peptide 2 (URP2), which appear to be absent in tetrapods [40]. Both A. burtoni URP1 and URP2 contain the urotensin II domain and the dibasic cleavage site necessary to produce the urotensin 2B neuropeptide. Injection of URP1 and URP2 peptides in Oncorhynchus mykiss (rainbow trout) found that these peptides had similar, but not identical, effects on locomotor behavior and cardio-respiratory physiology to UTS2, suggesting some subfunctionalization within this family in ray-finned fishes [45].

\section{Opioid peptide prohormone genes}

Duplicates of prepronociceptin (PNOC; PNOC1 and $P N O C 2)$, and single copies of proenkephalin (PENK) and prodynorphin $(P D Y N)$, were identified in A. burtoni. Similar to the Verasper moseri (barfin flounder) and $O$. mykiss [46], 3 versions of POMC (POMC1A, POMC1B, and $P O M C 2)$ were also identified. 
Table 1 Predicted A. burtoni prohormone families and duplication status

\begin{tabular}{|c|c|c|c|c|}
\hline Neuropeptide Family & $N G^{a}$ & $N D^{b}$ & Gene Symbols ${ }^{c}$ & References \\
\hline Apelin & 1 & 0 & APLN & [70] \\
\hline Augurin & 1 & 0 & AUGN & \\
\hline AVIT/Prokineticin & 2 & 0 & PROK1; PROK2 & \\
\hline Bombesin/Neuromedin-B/Ranatensin & 3 & 2 & GRP; NMB1; NMB2 & [113] \\
\hline Calcitonin & 8 & 4 & ADM1A; ADM1B; ADM2A; ADM2B; ADM5; CALCA; CALCB; IAPP & [114] \\
\hline CART & 6 & 6 & CARTPT1; CARTPT2; CARTPT3; CARTPT4; CARTPT5; CARTPT6 & [71] \\
\hline clpA/clpB family. Torsin subfamily. & 1 & 0 & TOR2A & \\
\hline Corticotrophin & 5 & 2 & CRH1A; CRH1B; UCN2; UCN3; UTS1 & {$[50,115-117]$} \\
\hline Endothelin/Sarafotoxin & 6 & 6 & EDN1A; EDN1B; EDN2A; EDN2B; EDN3A; EDN3B & [118] \\
\hline Gastrin/Cholecystokinin & 3 & 2 & CCK1; CCK2; GAST & [119] \\
\hline Ghrelin/Motilin-related & 2 & 0 & GHRL; MLN & {$[119,120]$} \\
\hline Glucagon & 8 & 4 & ADCYAPIA; ADCYAP1B; GCGIA; GCG1B; GCG2; GHRH; GIP; VIP & {$[35,37,121]$} \\
\hline Gonadotropin-releasing hormone & 3 & 0 & GNRH1; GNRH2; GNRH3 ${ }^{d}$ & {$[28,122-124]$} \\
\hline Granin & 9 & 4 & CHGA; CHGB; PCSK1N; SCG2A; SCG2B; SCG3; SCG5; VGF1; VGF2 & {$[73,125,126]$} \\
\hline Hepcidin & 5 & 5 & HAMP1; HAMP2; HAMP3; HAMP4; HAMP5 & [68] \\
\hline Insulin & 5 & 2 & IGF1; IGF2; IGF3 ${ }^{d}$ INS1; INS2 & {$[32,127]$} \\
\hline Kisspeptin/Galanin/Spexin & 4 & 2 & KISS2 $2^{d}$ GAL; SPX1; SPX2 & {$[61,62,128-130]$} \\
\hline Melanin-concentrating hormone & 2 & 2 & PMCH1; PMCH2 & [131] \\
\hline Natriuretic peptide & 6 & 4 & NPPA; NPPB; NPPC1; NPPC2; NPPC3; NPPC4 & [70] \\
\hline Neuropeptide B/W & 2 & 2 & $N P B 1 ; N P B 2$ & [53] \\
\hline Neurotensin & 1 & 0 & NTS & \\
\hline Neuromedin & 2 & 0 & NMS; NMU & [132] \\
\hline Neuropeptide Y & 4 & 4 & NPY1; NPY2; PYY1; PYY2 & {$[54,55]$} \\
\hline Nucleobindin & 3 & 2 & $N U C B 1 ; N \cup C B 2 A ; N \cup C B 2 B$ & \\
\hline Opioid & 7 & 5 & PDYN; PENK; PNOC1; PNOC2; POMC1A; POMC1B; POMC2 & {$[46-48,104,133-135]$} \\
\hline Orexin & 1 & 0 & HCRT & [136] \\
\hline Osteocrin & 1 & 0 & OSTN & \\
\hline Oxytocin/Vasopressin & 2 & 0 & AVP; OXT; & [137] \\
\hline Parathyroid & 6 & 4 & PTH1A; PTH1B; PTH2; PTHLH1; PTHLH2; PTHLH3 ${ }^{d}$ & {$[57,58,138,139]$} \\
\hline PDGF/NEGF growth factor & 13 & 10 & $\begin{array}{l}\text { FIGF; PDGFA1; PDGFA2; PDGFB1; PDGFB2; PDGFC; } \\
\text { PDGFD; PGF1; PGF2; VEGFA1; VEGFA2; VEGFC1; VEGFC2 }\end{array}$ & {$[33,34]$} \\
\hline Relaxin & 6 & 4 & INSL3; INSL5A; INSL5B; RLN1; RLN3A; RLN3B & {$[33,34,140]$} \\
\hline Rfamide peptide & 5 & 2 & NPFF; NPVF; QRFP; PRLH1; PRLH2 & {$[141-143]$} \\
\hline Somatostatin/Urotensin & 8 & 4 & SST1; SST2; SST3; SST5; URP1 ${ }^{d}$; URP2 ${ }^{d}$; UTS2A; UTS2B & {$[39,40]$} \\
\hline Tachykinin & 6 & 6 & TAC1A; TAC1B; TAC3A; TAC3B; TAC4A; TAC4B & [144] \\
\hline Thyrotropin-releasing hormone & 1 & 0 & TRH & [145] \\
\hline
\end{tabular}

${ }^{\mathrm{a} N}$ G: Number of identified gene sequences within family

${ }^{\mathrm{b}} \mathrm{N}$ D: Number of identified gene sequences within family that have been duplicated

${ }^{\mathrm{C}} \mathrm{Gene}$ Symbol: Based on Homo sapiens gene symbols where probable duplicated genes are denoted with either a number or lower case letter. Full gene names and symbols are provided in Additional file 2

${ }^{\mathrm{d}}$ Prohormones lacking direct mammalian counterparts

It is hypothesized that these opioid genes are related through two rounds of genomic duplication [47, 48]. All 3 POMC sequences lacked the melanocyte-stimulating hormone $(\mathrm{MSH})$ peptide, $\gamma-\mathrm{MSH}$, consistent with the loss of $\gamma$-MSH in ray-finned fishes [48]. Only 2 POMC versions were similar across species, suggesting these are duplicated copies from the teleost duplication and independent duplication events led to a second paralog.

Comparisons of $P O M C$ sequences have indicated that $P O M C 1 A$ and $P O M C 1 B$ are a result of a tandem 
duplication in the teleost lineage near when the Pleuronectiformes (e.g., flounders) split from Perciformes (e.g., cichlids) [18]. Further, Harris et al. [18] observed a tandem duplication within the POMC2 gene that encompassed part of the $\mathrm{N}$-terminal fragment, all of $\alpha$ $\mathrm{MSH}$, and part of the adrenocorticotropic hormone that arose before the radiation of cichlids but sometime after the radiation of Labridea (wrasses). A novel $\varepsilon-\mathrm{MSH}$ peptide was proposed [18], but this peptide is unlikely to occur or be bioactive in A. burtoni. While the proposed cleavage fits the RxxK motif that is cleaved as part of the known motif model [49], the sequence lacks a suitable amidation site that is present in all MSH peptides.

\section{Corticotropin family}

Duplicated copies of corticotropin-releasing hormone 1 (CRH1A and CRH1B), and single copies of urotensin 1 (UTS1), urocortin 2 (UCN2), and urocortin 3 (UCN3) genes were identified. Alignment to the mammalian versions indicated $A$. burtoni CRH, UTS1, and UCN3 were similar to mammalian corticotropin-releasing hormone $(C R H)$, urocortin 1 (UCN1), and $U C N 3$, respectively. Similar to Boorse et al. [50], UCN2 was intermediate between mammalian $U C N 2$ and $U C N 3$ with only the $U C N 2$ domain shared. It is proposed that a genome duplication prior to the divergence of actinopterygian and sarcopterygian fishes gave rise to duplicated $U C N 3$ and $C R H$ genes $[50,51]$. In the case of $C R H$, one gene duplicate, $C R H 2$, was lost in teleost fishes and eutherian mammals, and $A$. burtoni CRH1A and CRH1B are likely duplicates of an ancestral CRH1 [51, 52].

\section{Neuropeptide B/W family}

We found duplicate versions of neuropeptide B $(N P B)$, $N P B 1$ and NPB2, but not neuropeptide W $(N P W)$ in $A$. burtoni. Both the prohormones and neuropeptide receptors are highly related [53]. Both $N P B$ and $N P W$ have been identified in the genome of Monodelphis domestica (opossum; NPB: [GenBank:XM_001379652.2]; NPW: [GenBank:XM_007499923.1]) and Xenopus laevis (African clawed frog; NPB: [GenBank:XM_002937305.3]; NPW: [GenBank:XM_004918054.2]). Although NPW was not identified in the avian genomes of G. gallus and Taeniopygia guttata (zebra finch), an NPW-like sequence is identified in Pseudopodoces humilis (ground tit; [GenBank:XM_005523213.1]). Homology searching in Latimeria chalumnae (coelacanth) also indicated both NPB ([GenBank:XM_005989108.1]) and NPW (match on scaffold01390 NCBI Reference Sequence: [GenBank:NW 005820400.1]). Thus, our findings in $A$. burtoni support that NPW either arose after the split of the teleosts from other vertebrates or was lost in the teleost lineage.

\section{Neuropeptide $Y$ family}

The neuropeptide $\mathrm{Y}$ family consists of neuropeptide $\mathrm{Y}$ $(N P Y)$, pancreatic prohormone (PPY), and peptide tyrosine-tyrosine $(P Y Y)$ that arose by gene duplication $[54,55]$. Two copies of NPY (NPY1 and NPY2) and two of PYY (PYY1 and PYY2) were identified in A. burtoni, as well as the ray-finned fish-specific pancreatic peptide Y, which has been recognized as a duplicate of $P Y Y$ [54]. $P P Y$ was not identified, consistent with a duplication event after tetrapod divergence [55]. The L. chalumnae sequence ([GenBank:XM_005992227.1]) containing the partial pancreatic polypeptide sequence reported by Larhammar and Bergqvist [56] was more similar to $P Y Y$ than the other neuropeptide $\mathrm{Y}$ family members.

\section{Parathyroid hormone family}

The parathyroid family consists of parathyroid hormone 1 (PTH1), parathyroid hormone 2 (PTH2) and parathyroid hormone-related hormone $(P T H L H)$ [57, 58]. Duplicate versions of PTH1 (PTH1A and PTH1B) and PTHLH (PTHLH1 and PTHLH2) were identified, and a single version $P T H 2$ were identified. In addition, a third PTHLH gene (PTHLH3) similar to the Danio rerio (zebrafish) predicted gene ([GenBank:XM_005168285.2]) was identified that had intermediate homology between the PTH and PTHLH genes and appears to have been lost in eutherian mammals $[57,58]$.

\section{RFamide and kisspeptin/galanin/spexin families}

The RFamide family consists of prohormones that produce $\mathrm{C}$-terminal arginine and amidated phenylalanine bioactive peptide $[59,60]$. It has been proposed that kisspeptin (KISS), GAL and spexin (SPXN) belong to the same family due to the sequence similarly of prohormones and receptors and that SPXN can activate the $G A L$ receptors [61]. The relationship between these families is undergoing further revision as it has been suggested that KISS and prolactin-releasing hormone $(P R L H)$ may not belong in the RFamide family [62].

Duplicate copies of SPXN (SXPN1 and SPXN2) and PRLH (PRLH1 and PRLH2), and single copies of neuropeptide FF-amide peptide precursor (NPFF); NPVF; pyroglutamylated RFamide peptide (QRFP), GAL and KISS2 were identified. There was no evidence for an $A$. burtoni galanin-like peptide (GALP) or kisspeptin-1 (KISS1).

The presence of KISS2 and the lack of KISS1 in A. burtoni is consistent with KISS gene evolution [63]. Interestingly, some ray-finned fish and Ornithorhynchus anatinus (platypus) have both KISS1 and KISS2, whereas eutherian mammals have maintained only KISS1. There is some indication of a KISS2-like gene in apes [64] that may be a pseudogene because it is a single exon compared to the 2 exons in other species. The presence of a single GAL gene appears to be consistent with other teleost species, 
with the exception of Cypriniformes (e.g., D.rerio and Carassius auratus (goldfish)) that appear to have a duplication of GAL (GAL1 and GAL2) [16, 65]. Two GAL isoforms were determined from EST evidence. The longer of the A. burtoni splice isoforms introduces an in-frame insertion of $72 \mathrm{bp}$ due to alternative splicing of exon 3 and 4. A similarly generated splice isoform has also been identified in other teleosts and avian species $[65,66]$.

The lack of evidence of GALP is consistent with our previous studies suggesting it may only be present in some eutherian mammals [67]. The partial L. chalumnae GALP, predicted by Kim et al. [61], appears to be a duplicated GAL gene. Homology indicated that it is more similar to the X. laevis GAL2 ([GenBank:XM_004916293.1]) than the X. laevis GAL1 ([Genbank:XM_002941642.3]). It is likely that this is a duplicated GAL gene rather than GALP because the $X$. laevis sequence contains the galanin message associated peptide (GMAP), which is not present in mammalian GALP, and because X. laevis and L. chalumnae GAL2 genes lack synteny with $H$. sapiens GALP [61].

\section{Hepcidin antimicrobial peptide}

Five $H A M P$ sequences were identified in $A$. burtoni (HAMP1, HAMP2, HAMP3, HAMP4 and HAMP5), however 2 sequences (HAMP2 and HAMP4) were virtually identical. These 2 sequences were located on different contigs and the location of one sequence at the end of a contig indicates these may be the result of an assembly error. The different HAMP versions are a consequence of WGD and additional tandem gene duplication, possibly related to host-pathogen interaction or changes in oxygen availability $[68,69]$.

\section{Natriuretic peptides}

Single copies of natriuretic peptide A (NPPA) and natriuretic peptide $\mathrm{B}(N P P B)$ were identified as well as the expected 4 copies of natriuretic peptide C (NPPC1, NPPC2, NPPC3, and NPPC4) [70]. Multiple chromosomal duplications resulted in 4 versions of the ancestral $N P P C$ gene with the subsequent loss of the NPPC1, $N P P C 2$ and $N P P C 3$ versions in tetrapods. Prior to the $N P P C 3$ loss in tetrapods, tandem duplication of the $N P P C 3$ gene gave rise to $N P P A$ and $N P P B$ [70], which is evident by less than 6,000 bps between these genes in the $A$. burtoni assembly.

\section{CART prepropeptide}

Similar to O. latipes, 6 different CART prepropeptide (CARTPT) prohormones were identified in A. burtoni. CARTPT1 was most similar to mammalian CARTPT than the other CARTPT prohormones identified. The relationship between different prohormones is unclear because all versions are located on different scaffolds in the current $A$. burtoni genome assembly. Multiple sequence alignment suggests greater sequence similarity between two pairs of CARTPT prohomones: CARTPT1 with CARTPT2, and CARTPT3 with CARTPT4. O. latipes also has 6 CARTPT copies [71] and D. rerio has 4 CARTPT copies [72].

\section{The granin family}

A. burtoni orthologs were identified for the mammalian granin family members chromogranin A $(C H G A)$, chromogranin B $(C H G B)$, secretogranin II (SCG2), secretogranin III (SCG3), secretogranin V (SCG5), proprotein convertase subtilisin/kexin type 1 inhibitor (PCSK1N), and vascular endothelial growth factor $(V G F)$ [73]. In addition, two copies of SCG2 (SCG2A and SCG2B) and VGF (VGF1 and VGF2) were found. Although a match for GNAS complex locus was found, there was no homology to the neuroendocrine secretory protein- 55 isoform. Similar to Kudo et al. [74], there was limited similarity between mammalian and the identified versions of PCSK1N genes; the A. burtoni version contained PEN-like and little-LEN peptides but lacked the SAAS peptides. This suggests that the gain of PCSK1N functionality is only in mammals.

\section{Salusin peptides and torsin family 2 , member A}

Unlike most prohormones, the TOR2A gene undergoes alternative splicing where one isoform is cleaved into the salusin peptides [75]. While the A. burtoni TOR2A gene was identified, there was no predicted isoform that could produce the salusin peptides. Subsequent searches for the salusin peptides in other species indicate that this isoform may have only arisen within eutherian mammals.

\section{Prohormone convertases family}

The bioactive peptides produced from the prohormones described above depend on the specific set of prohormone convertases (as well as other enzymes responsible for post-translational modifications) present [76]. A search of the $A$. burtoni genome identified PCSK type 1 (PCSK1), 2 (PCSK2), 5 (PCSK5), 7 (PCSK7), and 9 (PCSK9) genes. There were no matches to mammalian PCSK type 4 and 6 genes. Generally these PCSK genes showed higher similarity to their mammalian counterparts than to each other. Two copies of PCSK5 (PCSK5A and PCSK5B) and FURIN (FURIN1 and FURIN2) were identified and single copies of PCSK1, PCSK2, PCSK7, PCSK9, and membrane-bound transcription factor peptidase, site 1 (MBTPS1) were identified. Only the $P C S K 5 B$ gene was similar to the mammalian version, with PCSK5A appearing to be a paralog of the mammalian gene. An identified PCSK-like gene may be an incomplete gene or an assembly error because the prediction lacks the FU domains that are present in other PCSK genes. 
Tandem mass spectrometry peptide identification in the pituitary

Peptides resulting from the previously detected prohormones were identified using MS-based peptidomics [7779]. We first assessed the feasibility of peptidomic experiments by testing peptide content in freshly frozen individual pituitaries using matrix-assisted laser desorption/ ionization (MALDI) time-of-flight (TOF) MS. Mass fingerprinting of peptides measured by direct tissue MALDI-TOF MS detected and putatively identified 46 peptides from 12 proteins, including 29 peptides from POMC1A (Fig. 1), and all peptides were subsequently confirmed by tandem MS (Additional file 3: Table S2).

Tandem MS detected a total of 680 peptides from 620 unique peptide sequences after accounting for different modifications on the same sequence (Additional file 4: Table S3). There were 22 peptides detected with a single amino acid substitution compared to the predicted sequence from the genome, which may be due to genetic differences between the $A$. burtoni populations used for tandem MS and genome sequencing. The unique peptide sequences were matched to 125 unique proteins. Proteins identified by more than 9 unique characterized peptides each are listed in Table 2.

Most of the peptides detected (164) were derived from $P O M C$ prohormones. There were 42 peptides with at least one post-translational modification. No $\alpha-M S H$ was detected but an $\mathrm{N}$-terminal peptide of POMC1A was detected, which was expected from the sequence [48]. Subsequent alignment of all $P O M C$ peptides indicated that most of these were derived only from POMC1A (120), 39 peptides were derived from an identical peptide region in $P O M C 1 A$ and $P O M C 1 B$, and 7 peptides with an identical sequence in $P O M C 1 A, P O M C 1 B$, and $P O M C 2$. There were no peptides uniquely identified to $P O M C 1 B$ and $P O M C 2$, indicating that $P O M C 1 B$ and $P O M C 2$ prohormones were not present at detectable levels.

Both pro-melanin-concentrating hormone 1 (PMCH1) and pro-melanin-concentrating hormone 2 (PMCH2) were detected with 24 and 14 peptides, respectively. In addition, a single peptide was detected that shared a sequence between 2 copies of melanin-concentrating

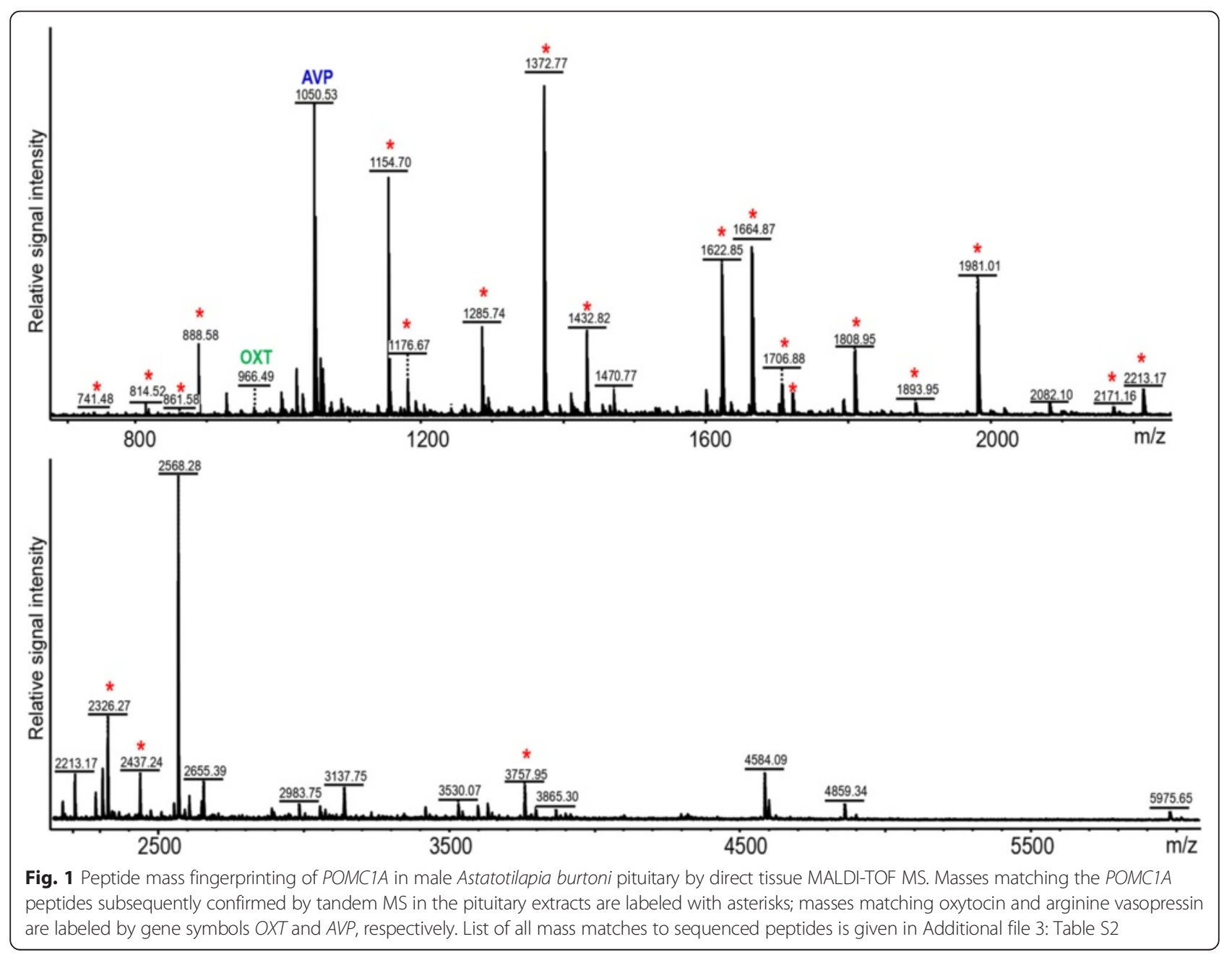


Table 2 Pituitary proteins confirmed by the highest number of peptides using tandem MS

\begin{tabular}{|c|c|c|c|c|c|}
\hline Type & Symbol & N. peptides & Gene locus & Accession No. & Gene name \\
\hline Prohormone & $A V P$ & 16 & LOC102310610 & NP_001273257.1 & arginine vasopressin \\
\hline Prohormone & $C H G B$ & 9 & LOC102304831 & XP_005917770.1 & chromogranin B \\
\hline Prohormone & GNRH1 & 9 & LOC102291227 & NP_001273225.1 & gonadotropin-releasing hormone 1 \\
\hline Prohormone & NUCB2B & 9 & LOC102313482 & XP_005931689.1 & nucleobindin $2 \mathrm{~B}$ \\
\hline Prohormone & OXT & 26 & LOC102312886 & XP_005919106.1 & oxytocin \\
\hline Prohormone & PCSK1N & 11 & LOC102305204 & XP_005931188.1 & $\begin{array}{l}\text { proprotein convertase subtilisin/kexin } \\
\text { type } 1 \text { inhibitor }\end{array}$ \\
\hline Prohormone & PMCH1 & 24 & LOC102310003 & XP_005921781.1 & pro-melanin-concentrating hormone 1 \\
\hline Prohormone & PMCH2 & 14 & LOC102314388 & XP_005934290.1 & pro-melanin-concentrating hormone 2 \\
\hline Prohormone & POMCIA & 164 & LOC 102296817 & NP_001273262.1 & proopiomelanocortin $1 \mathrm{~A}$ \\
\hline Prohormone & $S C G 2 A$ & 13 & LOC102306907 & XP_005948590.1 & secretogranin lla \\
\hline Prohormone & $S C G 2 B$ & 12 & LOC102295815 & XP_005938347.1 & secretogranin llb \\
\hline Prohormone & SCG3 & 22 & LOC102313744 & XP_005949052.1 & secretogranin III \\
\hline Prohormone & $T A C 1 B$ & 10 & none & none & tachykinin precursor 1B \\
\hline Other & ACTB & 13 & LOC102293972 & XP_005952745.1 & actin, cytoplasmic 1-like isoform X1 \\
\hline Other & $C A L R$ & 12 & LOC102296215 & XP_005936722.1 & calreticulin-like \\
\hline Other & $H B A 1$ & 21 & LOC102301295 & XP_005920277.1 & hemoglobin subunit alpha-A-like \\
\hline Other & $H B B$ & 13 & LOC102301591 & XP_005920278.1 & hemoglobin subunit beta-A-like \\
\hline Other & HSP9OB1 & 15 & LOC102308602 & XP_005929149.1 & endoplasmin-like \\
\hline Other & PDIA3 & 20 & LOC102293196 & XP_005931703.1 & protein disulfide-isomerase A3-like \\
\hline Other & PDIA4 & 9 & LOC102309651 & XP_005912150.1 & protein disulfide-isomerase A4-like \\
\hline Other & $P P I B$ & 9 & LOC102303154 & XP_005931742.1 & peptidyl-prolyl cis-trans isomerase B-like \\
\hline
\end{tabular}

hormone $(\mathrm{MCH}), \mathrm{MCH} 1$ and $\mathrm{MCH} 2$. This peptide corresponds to the $\mathrm{MCH}$ encoding sequence at the C-terminal of both $\mathrm{MCH}$ prohormones. Peptides from PMCH1 corresponded to the same region as mammalian neuropeptideglycine-glutamic acid. The predicted $\mathrm{PMCH} 2$ sequence could not form this neuropeptide-glycine-glutamic acid peptide, and, unlike the mammalian prohormone sequence, this $P M C H 1$ peptide is surrounded by dibasic amino acids. Neither $P M C H 1$ nor $P M C H 2$ prediction included a peptide corresponding to neuropeptide-glutamic acid-isoleucine.

Both arginine vasopressin and oxytocin neuropeptides were detected as well as other peptides from their respective prohormones. Overall, OXT and AVP provided 26 and 16 unique peptides, respectively. Oxytocin and arginine vasopressin peptides were detected, as well as C-terminal peptides corresponding with copeptin from both OXT and $A V P$. The remaining peptides detected were $O X T$ fragments from the neurophysin 1 peptide. The detection of these peptides and the similarity of prohormone sequences indicate that mammalian $O X T$ has undergone greater divergence than AVP since the tetrapod divergence.

The other prohormone with multiple peptides was $S C G 3$, in which the majority of the peptides were near the signal peptide or near the C-terminus. The peptides near the signal peptide likely correspond to polypeptides resulting from cleavage at the arginine pair following removal of the signal peptide. Peptides from this region have also been detected in mammals (e.g., Fricker et al. [80]). However, since neither region had obvious NeuroPred-predicted [81] cleavage sites, it is unclear whether these are post-processing degradation products of the large SCG3 peptide, or resulted from posttranslational enzymatic cleavage.

Examination of the peptides from V-set and transmembrane domain-containing protein 2-like protein-like (VSTM2A) indicates a novel C-terminal peptide (Fig. 2). Evaluation of the predicted protein sequence identified an immunoglobulin domain and dibasic sites commonly cleaved by prohormone convertases, and a signal peptide was predicted using SignalP v4.1 [82]. This protein is longer than the mammalian VSTM2A sequence. The observed peptides corresponded to regions between cleavage sites predicted by NeuroPred [81], with both vertebrate and invertebrate models. This predicted gene was found with similar length and dibasic sites in some ray-finned fish species (e.g., O. latipes: [GenBank:XM_004070260.2]; Poecilia reticulata (Guppy): [GenBank:XM_008413143.1]; Cynoglossus semilaevis (tongue sole): [GenBank:XM_008318238.1]; Xiphophorus maculatus (southern platyfish): [GenBank:X M_005807649.1]). However, some species, such as Takifugu 


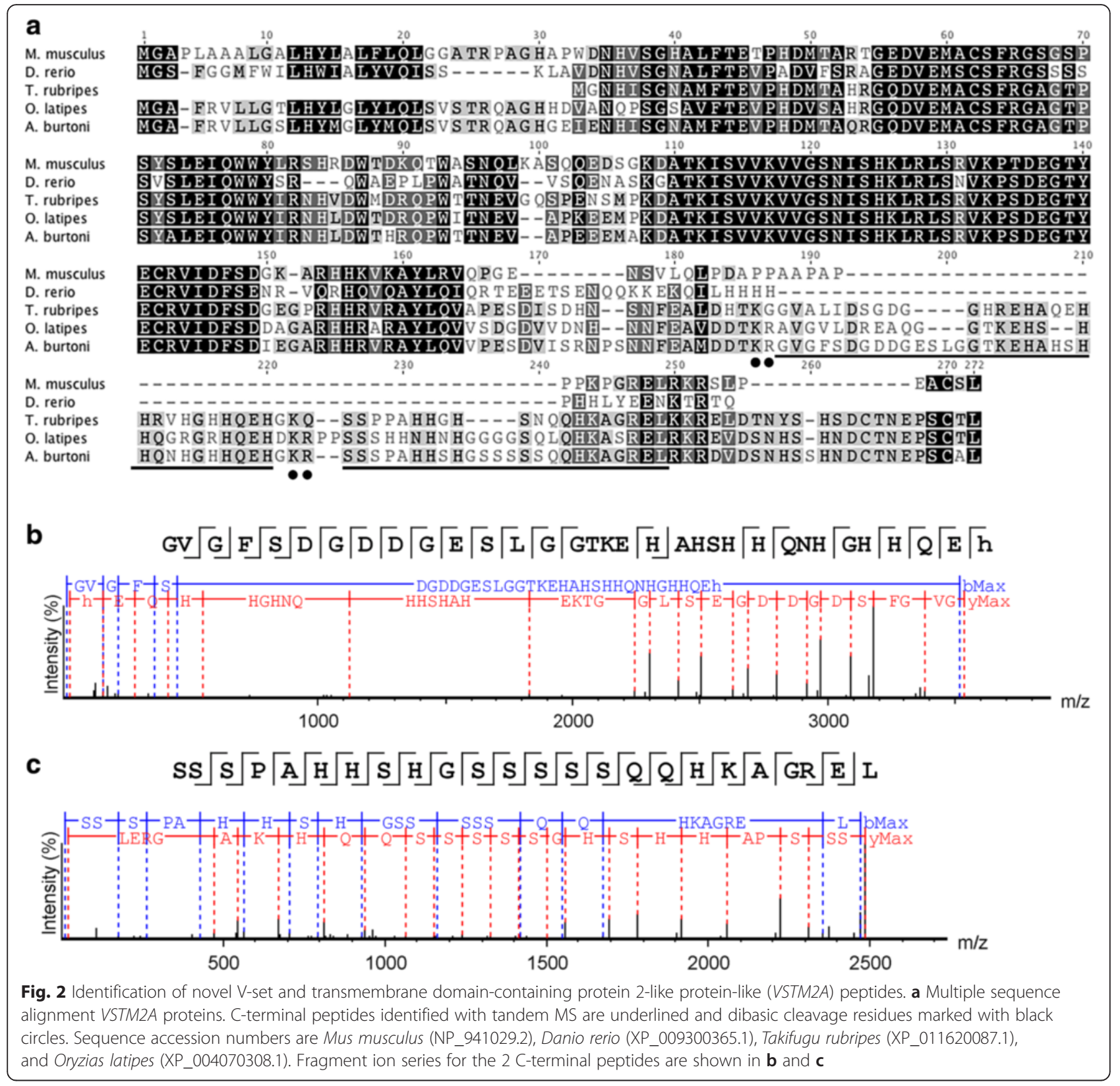

rubripes (Japanese puffer) and Lepisosteus oculatus (spotted gar), appear to lack one or more of the dibasic sites, and others such as $L$. chalumnae and $D$. rerio lack any match to the region containing these peptides.

Tandem MS identified peptides from alternatively spliced forms of $C H G B$ and $G A L$. The $C H G B$ isoforms are identical except that the longer $C H G B$ isoform retains an intron that contains an MS-identified peptide. The galanin peptide detected by MS is encoded by the shorter A. burtoni splice isoform, and this peptide is distinguished by two aspects. First, the N-terminal 14 amino acids of galanin are highly conserved across vertebrates and are important for receptor binding [14].
Previously, the only known exception was in Thunnus albacares (yellowfin tuna), which has a serine to alanine substitution at position 6 [83]. A. burtoni galanin is also an exception, with a leucine to methionine substitution at position 4 (Fig. 3a). Second, the A. burtoni peptide is 32 amino acids long, making it the longest sequenced galanin peptide (Fig. 3b). The length of galanin is highly conserved across vertebrate evolution at 29 amino acids and previously only $H$. sapiens galanin was known to exceed this length [84]. Our understanding of galanin receptor function in teleosts is only beginning to emerge [85], therefore, the significance of this substitution is unknown. If $A$. burtoni galanin receptors are similar to $D$. 


\begin{tabular}{|c|c|c|}
\hline Species & Amino acid sequence & Leng \\
\hline C. auratus GAL1A & -------------------- HAIDSHRSLGDKHGVA- & 29 \\
\hline C. auratus GAL1B & GWTLNSAGYLLGPRRIDHLIQIKDSPSARGRE-----DLLGQYAIDSHRSLGDKHGVA- & 53 \\
\hline T. albacares GAL* & GWTLNAAGYLLGP------------------------HGID-----GHRTLGDKPGLA- & 29 \\
\hline A. burtoni GAL_alt* & GWTMNSAGYLLGP------------------------HGLDG--LHGHTRLGDKPGLA- & 32 \\
\hline A. burtoni GAL & GWTMNSAGYLLGPRRIDHLIQIKDSPSARGRDELVTQYGLDG--LHGHTRLGDKPGLA- & 56 \\
\hline G. gallus GAL2* & GWTLNSAGYLLGP------------------------HA-----VDNHRSFNDKHGFT- & 28 \\
\hline G. gallus GAL1 & GWTLNSAGYLLGPRRIDHLLMIKEMPIARGRE-----EAPG-AYVDNHRSFNDKHGFT- & 52 \\
\hline S. scrofa GAL* & GWTLNSAGYLLGP------------------------HA-----IDNHRSFHDKYGLA- & 29 \\
\hline H. sapien GAL* & GWTLNSAGYLLGP------------------------HA-----VGNHRSFSDKNGLTS & 30 \\
\hline
\end{tabular}

b

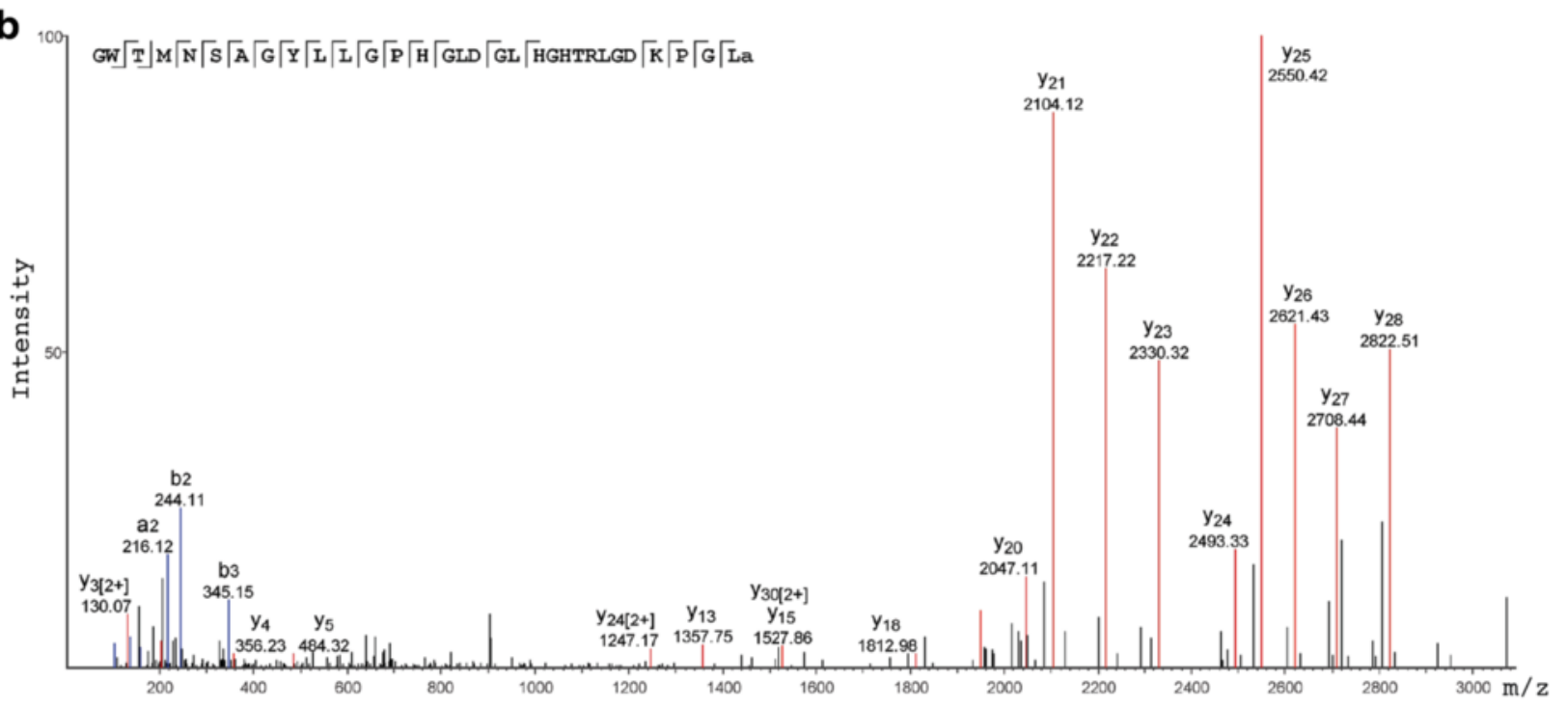

C

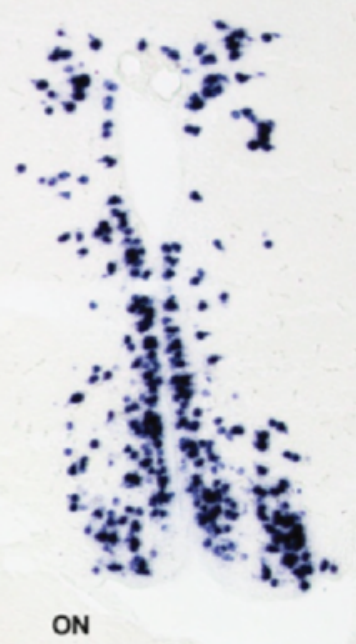

Fig. 3 (See legend on next page.)

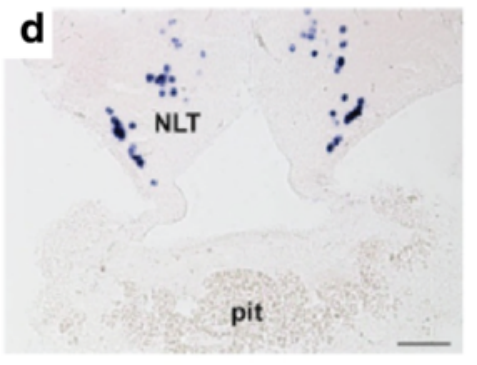

e

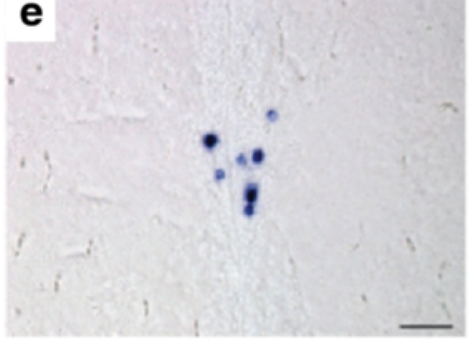

f

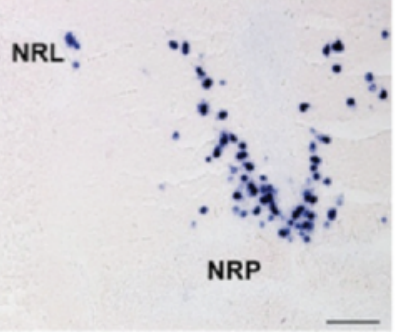

g

VL

cC

\section{gth}

3 
(See figure on previous page.)

Fig. 3 Characterization of galanin mature peptide and GAL prohormone expression. a Alignment of vertebrate galanin peptides. Astatotilapia burtoni sequences have a bolded species label. Sequences supported by peptide sequencing are marked with asterisks $(*)$. Alignment made with the ClustalW program. $\mathbf{b}$ The A. burtoni galanin peptide fragmented and sequenced via tandem MS. $\mathbf{c}-\mathbf{g}$ Representative transverse sections showing GAL-expressing neurons in the brain and pituitary. GAL-expressing cells were found in the preoptic area $\mathbf{c}$, nucleus of the lateral tuberalis $(N L T) \mathbf{d}$, medial region of the nucleus of the lateral recess (NRL) and in the region dorsal to the nucleus of the posterior recess (NRP) $\mathbf{e}$, region of the periventricular nucleus of the posterior tuberculum $\mathbf{f}$, and in the hindbrain along the lateral border of the vagal lobe $(\mathrm{VL}) \mathbf{e}$. CC, cerebellar crest; ON, optic nerve; pit, pituitary. Scale bars $=100 \mu \mathrm{m}$ c; $25 \mu \mathrm{m} \mathbf{d}-\mathbf{g}$

rerio galanin receptors, and display affinity for galanin and spexin peptides, then the unusual form of $A$. burtoni galanin may suggest that there has been pronounced ligand-receptor co-evolution in the GAL/SPXN system in cichlids.

Detection of numerous peptides from non-secreted proteins such as hemoglobin subunit- $\alpha$-like and $\beta$-like, endoplasmin-like, actin, and cytoplasmic 1-like protein, among others in the pituitary, is not surprising due to their ubiquitous nature. High protein sequence coverage was obtained for some of these proteins due to multiple detected peptides (Additional file 3: Table S2). In fact, enzymatic processing of cytosolic proteins can generate non-classical peptides that may have biological activity [86, 87]. In particular, hemoglobin-derived peptides, such as hemorphins and hemopressins, have diverse functions in various tissues and are expressed by neurons $[87,88]$. Therefore, $A$. burtoni peptides from hemoglobin subunit$\alpha$-like (20 unique peptide sequences) and hemoglobin subunit- $\beta$-like ( 8 peptides) may in part represent bioactive peptides. The disulfide-isomerase proteins, protein disulfide-isomerase A3-like (18 unique peptide sequences), and protein disulfide-isomerase A4-like (9 peptides), regulate folding and redox state of proteins via formation, reduction, or isomerization of disulfide bonds [89]. Endoplasmin (15 unique peptides) is a molecular chaperone involved with the processing and transport of secreted proteins [90]. Actin, cytoplasmic 1-like (12 peptides), possibly reflects the role of actin in vesicle transport [91]. Calreticulin (12 peptides) is involved with maintaining adequate calcium levels in the system, and functions as a chaperone in the folding of other proteins [92].

\section{Localization of galanin prohormone expression}

Galanin is one of the better characterized peptides within ray-finned fishes; having identified the mature $A$. burtoni galanin peptide, we next sought to identify GALexpressing cells in the $A$. burtoni brain using in situ hybridization (Fig. $3 \mathrm{c}-\mathrm{g}$ ). The distribution of galanin in many ray-finned fish species has been investigated primarily through detection of galanin-like immunoreactivity using anti-porcine galanin antibodies [16]. These studies have shown that in ray-finned fish, pituitary galanin is exclusively neural in origin, rather than both neural and pituitary-derived, as seen in mammals [14]. The Xiphophorus and Anableps genera may be exceptions [93, 94]. In situ hybridization of the A. burtoni pituitary supports all pituitary galanin in this species being neural-derived (Fig. 3d).

Neuroanatomical locations of GAL cells in the A. burtoni brain were determined according to brain atlases from Burmeister et al. [95] and Cerdá-Reverter et al. [96]. The most anterior cell population identified was in the anterior preoptic area (POA) (Fig. 3c). Along the dorsal-ventral axis, this population spanned from the anterior commissure and approached the ventral edge of the brain. This group of cells displayed the most intense signal of all populations, as well as the greatest diversity in cell soma diameter $(10-30 \mu \mathrm{m})$. Moving posteriorly, a small, sparse set of cells was present in the nucleus of the lateral tuberalis (NLT) (Fig. 3d). A few, faintlystained cells were also observed along the midline, in the periventricular nucleus of the posterior tuberculum (Fig. 3e). In the caudal hypothalamus, GAL-expressing cells were distributed in the anterior portion of the nucleus of the lateral recess (NRL), and directly dorsal to the nucleus of the posterior recess (NRP) (Fig. 3f). The most posterior group was found in the hindbrain, bordering the vagal lobe (Fig. 3g). Hindbrain galanin cells have been previously described in the locus coeruleus of cyprinodonts [97].

The presence of galanin-expressing cells in the POA and NLT is conserved across ray-finned fishes. In contrast, the presence and locations of more posterior populations exhibits greater diversity across ray-finned fishes. The NRL and NRP are considered components of the fish homolog to the nonmammalian vertebrate paraventricular organ, which contains galanin-immunoreactive cells in amphibians [98, 99]. An NRL population has been described in C. auratus [100], and both NRP and NRL populations described in Anguilla anguilla (eel) [101], Apteronotus leptorhynchus (brown ghost knifefish) [102], and O. mykiss [103]. Only the POA and NLT populations were identified in the non-haplochromine cichlid Alcolapia grahami (Lake Magadi tilapia) [97]. The lack of more caudal populations in A. grahami could be due to differences in specificity between techniques, diversification of the galanin system within cichlids, or a combination of the two. 


\section{Subfunctionalization of POMC prohormones}

We show here the first exploration of three $P O M C$ prohormones in the same species on the cellular level in the brain and pituitary using in situ hybridization (Table 3). Expression of all three POMC prohormones was found in both the corticotrope (rostral pars distalis)- and melanotrope (pars intermedia)-containing regions of the $A$. burtoni pituitary (Fig. 4). POMC1B showed the most intense signal in the pituitary, particularly in the pars intermedia, which is consistent with reverse transcription polymerase chain reaction (RT-PCR) results [18]. Similarly, expression of three $P O M C$ prohormones of $V$. moseri was detected in whole pituitary samples [104].

Localization of $P O M C$ prohormones within the brain showed that POMC1A and POMC1B occurred in the same locations, while $P O M C 2$ was more widely expressed. $P O M C 1 A$ and $P O M C 1 B$ expression were restricted to two hypothalamic nuclei, the NLT and rostral anterior tuberal nucleus (ATn) (Fig. 4). There were numerous small (4$10 \mu \mathrm{m}$ diameter) $P O M C 1 A$ and $P O M C 1 B$ cells in the ventral part of the NLT (NLTv) above the infundibular recess and pituitary, and a smaller population of larger neurons $(10-15 \mu \mathrm{m}$ diameter) located along the midline in the most rostral part of the ATn near the horizontal commissure. This expression pattern matches that of the single POMC1 gene in Tetraodon nigroviridis

Table 3 Localization of the proopiomelanocortin (POMC) gene family in the brain and pituitary of Astatotilapia burtoni

\begin{tabular}{|c|c|c|c|}
\hline Brain Region $^{a}$ & POMCIA & POMC1B & $P O M C 2$ \\
\hline \multicolumn{4}{|l|}{ Telencephalon } \\
\hline Dm & $-b$ & - & + \\
\hline Dld & - & - & + \\
\hline Dlg & - & - & + \\
\hline Dlv & - & - & + \\
\hline \multicolumn{4}{|l|}{ Diencephalon } \\
\hline POA & - & - & + \\
\hline NLT & + & + & + \\
\hline ATn & - & - & + \\
\hline \multicolumn{4}{|l|}{ Pituitary } \\
\hline RPD & + & + & + \\
\hline $\mathrm{Pl}$ & + & + & + \\
\hline \multicolumn{4}{|l|}{ Mesencephalon } \\
\hline $\mathrm{T}$ & - & - & + \\
\hline Metencephalon & - & - & - \\
\hline \multicolumn{4}{|c|}{ Rhombencephalon } \\
\hline NCC & - & - & + \\
\hline
\end{tabular}

${ }^{a}$ Brain Region: ATn anterior tuberal nucleus, Dm, medial part of the dorsal telencephalon; Dld, Dlg, Dlv, dorsal, granular, and ventral zones of the lateral part of the dorsal telencephalon; NCC commissural nucleus of Cajal; NLT nucleus of the lateral tuberalis, POA preoptic area, PI pars intermedia, RPD rostral pars distalis, $T$ tectum

b +, detected; -, not detected (green spotted puffer) [105]. The range of POMC2 expression in the $A$. burtoni brain and pituitary encompassed that of the POMC1 genes but within the NLT, POMC2 expression was more predominant in the medial and inferior parts of the NLT, while POMC1s were localized to the NLTv. POMC2 expression also extended to the dorsolateral telencephalon, POA, tectum, and commissural nucleus of Cajal in the hindbrain (Additional file 5: Figure S1). This expression pattern is broader than that in T. nigroviridis, in which POMC2 is restricted to the POA [105].

Although all three POMC genes are expressed in the hypothalamus and the pituitary, the tandem MS results suggest that $P O M C 1 B$ and $P O M C 2$ peptide products are either not present, are at an undetectable level, or are expressed at different times than POMC1A in pituitary (Additional file 4: Table S3). Whether POMC1B and $P O M C 2$-derived peptides are present in other tissues or developmental stages remains to be explored. Increased brain POMC1A expression is associated with dominant status in adult $A$. burtoni [17], but it is unknown which brain regions contribute to this increase and whether POMC2 exhibits similar social statusdependent expression.

It remains to be determined what function the extrahypothalamic $P O M C$-expression serves, as well as whether $P O M C 1 A$ or $P O M C 2$ are generally more varied in expression pattern across teleosts. For example, $\beta$-endorphin-like immunoreactive cells have been described in the thalamus and cerebellum of other teleosts [106, 107]. Since the betaendorphin region of $P O M C 2$ has degenerated in many teleost lineages, it is unclear which prohormones are involved.

\section{Conclusions}

Our systematic survey of prohormone genes in the $A$. burtoni genome identified 167 sequences from 141 prohormone, 7 prohormone-related and 10 PCSK genes, with experimental evidence for numerous peptides derived from proteins encoded by many of these genes. In addition, tandem MS identified a possible novel fishonly neuropeptide from VSTM $2 A$. Identification of peptides across fish species will facilitate functional testing of prohormone families, and whether there are any synergistic or collective mechanisms contributing to fish behavioral diversity. Two thirds of prohormone families contain duplicate genes, most deriving from the teleost WGD, indicating that this gene group has retained duplicates nearly three times the genome-wide average. These duplicates may serve as substrates for behavioral and physiological diversification within fishes and may have contributed to the remarkable speciation in the African cichlid species. In the case of $P O M C$, we show that all three $A$. burtoni $P O M C$ genes are expressed in the hypothalamus and pituitary, but MALDI-TOF and 


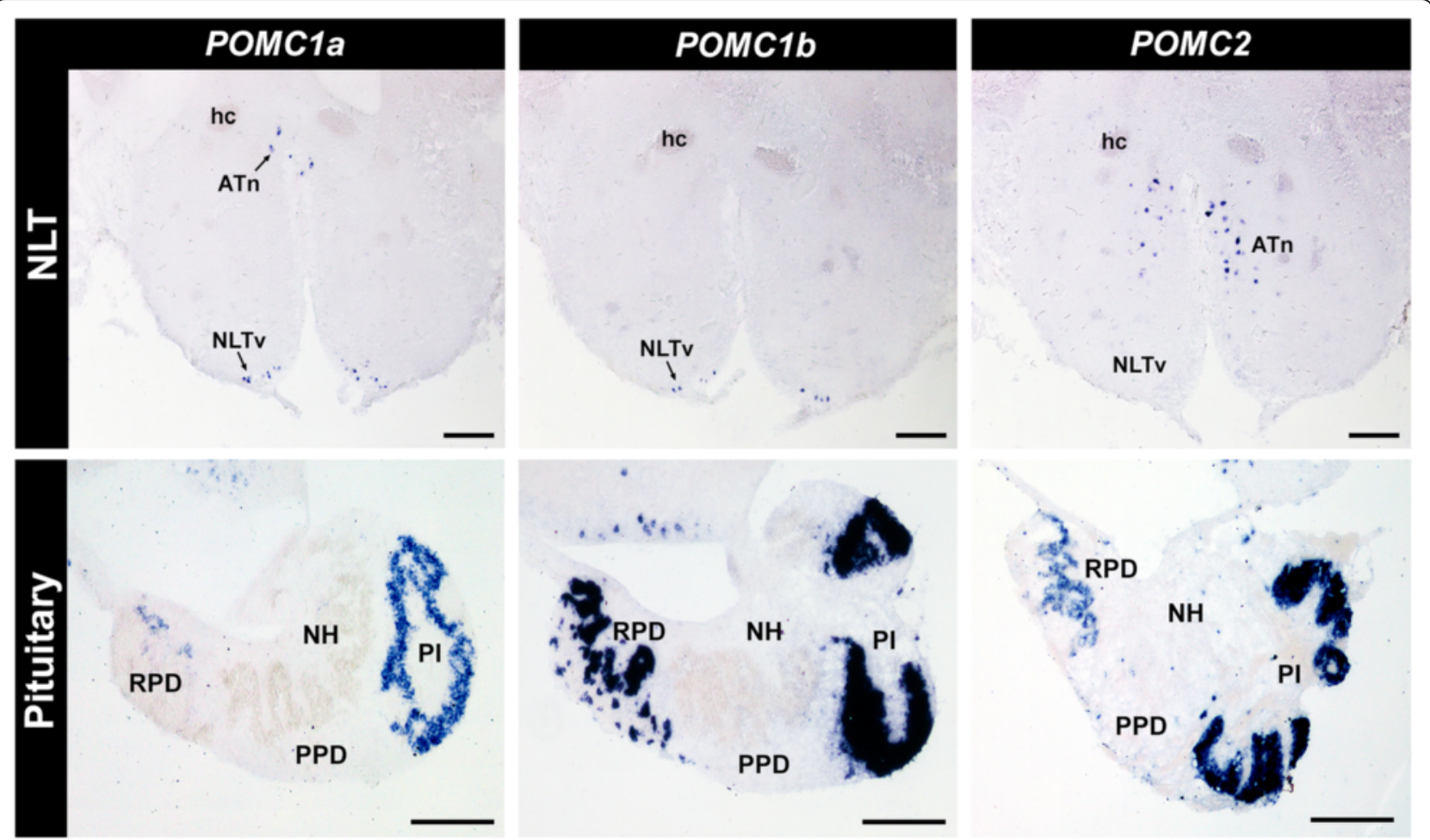

Fig. 4 Distribution of $P O M C 1 A, P O M C 1 B$, and $P O M C 2$ in the hypothalamus and pituitary gland of Astatotilapia burtoni. In situ hybridization shows POMCIA and POMC1B staining in NLTV and rostral ATn, and POMC2 in ATn. All three POMCs were found in the RPD and PI of the pituitary. Brain is $20 \mu \mathrm{m}$ transverse sections and pituitary is $20 \mu \mathrm{m}$ sagittal sections. ATn, anterior tuberal nucleus; hc, horizontal commissure; NH, neurohypophysis; NLT, nucleus of the lateral tuberalis; NLTV, ventral part of NLT; PI, pars intermedia; PPD, proximal pars distalis; RPD, rostral pars distalis;: Scale bars $=100 \mu \mathrm{m}$

tandem MS analysis of the pituitary suggest only one gene yields peptide products. Whether duplicates described in A. burtoni have undergone functional changes to give rise to different roles can be pursued in the wider context of the remarkably diverse African cichlids. The elucidation of A. burtoni's prohormone complement comes at an exciting time in cichlid research, and follows recent developments in genome assembly and transgenic technologies.

\section{Methods}

\section{Prohormone identification in silico}

Detection of teleost prohormones requires a two-phase approach to address the impacts of WGD, tandem duplication, reciprocal gene loss, and ligand-receptor coevolution. In the first phase, orthologs of known prohormones and any paralogs are identified. Subsequently, the second phase searches for any previously unidentified prohormone paralogs across different genomes.

In the first phase, 109 candidate genes, including known gene duplications and possible pseudogenes, were derived from prior mammalian and avian studies [67, 108, 109]. Each sequence was searched in the genome using our previously documented approach [67]. The protein sequence of each candidate gene was matched to the A. burtoni genome assembly using TBLASTN with the default settings
(E-value $<10$ and BLOSUM62 scoring matrix) and filtering disabled on the cichlid data site (http://cichlid.umd.edu/ cichlidlabs/kocherlab/bouillabase.html). All scaffold position matches with $E$-values $<1$ were evaluated as possible prohormone genes to account for WGD, tandem duplication, and ligand-receptor coevolution. Partial matches were also used to query the $A$. burtoni EST database in order to provide a more accurate match as well as any alternative splicing. When there was no suitable BLAST match to a candidate gene, the other cichlid resources were used to confirm any missing candidate gene or provide a more suitable candidate. The resulting matches were classified into similar matches based on $E$-value and percentage identity to separate duplicated genes from genes from the same prohormone family. Prohormone protein sequences were predicted using the gene parsing tool Wise2 [110]. The final predictions were then bioinformatically screened for alignments to related genes in the same neuropeptide family across other species to ensure the accuracy of prediction.

Compared to tetrapods, each teleost prohormone was expected to have two paralogous copies due to the third tetraploidization. In the second phase, candidate genes with only a single match were further investigated for reciprocal gene loss. Initially the searches were 
conducted using the genomic resources of the other sequenced cichlids, primarily $O$. niloticus. Unsuccessful searches were then conducted in other published fish genomes, notably Takifugu species, $T$. nigroviridis, $O$. latipes, Gasterosteus aculeatus (three-spined stickleback), and $D$. rerio, to determine if a more closely related version of the candidate gene could be found. Finally, a literature search was conducted to find evidence that the candidate gene is duplicated in any fish species. Any potential sequence was further screened using the previous tools and databases to confirm the presence of a duplicated prohormone.

\section{Animals}

Laboratory bred $A$. burtoni adults between 6 and $8.5 \mathrm{~cm}$ in standard length were housed in mixed sex communities in $60 \mathrm{l}$ aquaria under conditions mimicking natural habitat conditions $\left(26.5^{\circ} \mathrm{C} ; \mathrm{pH} 8.5 ; 12\right.$ h dark: $12 \mathrm{~h}$ light with full spectrum illumination) [111]. Animals were fed daily with cichlid pellets and flakes (AquaDine, CA, USA). Animals were euthanized by rapid cervical transection prior to pituitary and/or brain dissection.

\section{MALDI-TOF MS of pituitary tissue}

Freshly frozen individual pituitaries (three dominant males and three non-brooding females) were used for MALDI-TOF MS. Each pituitary was transferred onto a MALDI sample plate, divided into $10-15$ pieces using electrolytically sharpened tungsten needles, each tissue piece was transferred onto a new sample spot and mixed with $0.5 \mu \mathrm{l}$ of MALDI matrix (2,5-dihydroxybenzoic acid, $50 \mathrm{mg} / \mathrm{ml}$ of $50 \%$ acetone). Spectra were manually acquired on a Bruker ultrafleXtreme mass spectrometer equipped with a smartbeam- $\mathrm{II}^{\mathrm{Tm}}$ laser (Bruker Daltonics, MD, USA) operated at $1 \mathrm{kHz}$ speed in reflectron mode. External calibration was performed using Bruker Peptide Mix II standards in identical matrix.

\section{Pituitary peptide extraction}

Pituitaries were rapidly dissected from a second cohort of 5 adult animals ( 1 male, 4 females) and homogenized in $0.25 \mathrm{M}$ acetic acid (Sigma-Aldrich, CA, USA) using a Dounce homogenizer. Homogenates were pooled and then centrifuged for $30 \mathrm{~min}$ at $4{ }^{\circ} \mathrm{C}$ and $15,000 \times \mathrm{g}$. The supernatant $\mathrm{pH}$ was adjusted to $\sim 4$ using $1 \mathrm{M} \mathrm{NaOH}$ (Fisher, PA, USA) and desalted using Pierce C18 Spin Columns (Pierce, IL, USA) according to manufacturer's instructions. Column eluate was then dried (Savant SpeedVac, Thermo Scientific, Waltham, MA, USA) and reconstituted in $0.1 \%$ formic acid (Sigma-Aldrich).

\section{Pituitary peptide analysis by LC-MS/MS}

Samples were first acidified and purified on stage tips and eluted in $60 \%$ acetonitrile/40 \% $\mathrm{H}_{2} \mathrm{O}$, fractions were then dried (SpeedVac, Thermo Scientific) and reconstituted in $2 \%$ acetonitrile/97.8 \% $\mathrm{H}_{2} \mathrm{O} / 0.2 \%$ formic acid and injected onto a self-packed $15 \mathrm{~cm} \mathrm{C18}$ analytical column with a flow rate of $300 \mathrm{~nL} / \mathrm{min}$ directly infused into the mass spectrometer. Ultra performance liquid chromatography (UPLC) was performed using a Waters Acquity system (Waters, Milford, MA). The electrospray ionization (ESI) ion trap (IT) mass spectrometer (LTQ Orbitrap Velos; Thermo Scientific) was set in data-dependent mode to fragment the top 8 most intense, multiply charged ions using higher-energy collisional dissociation (HCD). The survey scan mass resolution was set to $60 \mathrm{~K}$ and the $\mathrm{HCD}$ fragment ion resolution to $7.5 \mathrm{~K}$.

\section{Bioinformatic peptide identification from the tandem MS data}

We performed the peptide identification on the tandem MS data exported as an mzXML file using PEAKS Studio software versions 5.3 and 7.0 (Bioinformatics Solutions, Waterloo, Canada). The PEAKS workflow included creation of de novo sequence tags that were then queried against a database of predicted $A$. burtoni prohormones and a database of NCBI-predicted proteins from the AstBur1.0 assembly using both standard (PEAKS DB) and homology (SPIDER) searches [112]. Standard search identified the peptides whose sequences matched those in a database, while homology search revealed peptides with slightly different sequences, which could be due to polymorphism or database error. Search parameters included $20 \mathrm{ppm}$ mass error tolerance for monoisotopic precursor ions and 0.1 $\mathrm{Da}$ for fragment ions, precursor charge state $1-5$, no enzyme cleavage, and a maximum of three variable modifications (pyroglutamate from $\mathrm{E}$ and $\mathrm{Q}$, acetylation of $\mathrm{N}$-terminus or lysine, disulfide bond, oxidation and amidation). The search results were filtered with $-10 \lg P$ of 20 ; all tandem MS spectra with scores lower than 30 were manually inspected and false positives removed.

\section{Tissue preparation for in situ hybridization}

Brains and pituitaries from 4 adult A. burtoni (2 males, 2 females) were prepared for GAL in situ hybridization and brains and pituitaries from an additional group of 5 adults ( 2 males, 3 females) for all POMCs. These animals were separate from those used for MS experiments. Tissues were fixed in $4 \%$ paraformaldehyde overnight at $4{ }^{\circ}$ $\mathrm{C}$, rinsed in PBS, and then cryoprotected with $30 \%$ sucrose overnight at $4{ }^{\circ} \mathrm{C}$. Tissues were then embedded in Tissue Tek OCT media (Sakura Finetek, MA, USA) in vinyl specimen molds (Sakura Finetek) and frozen on dry ice. Tissues were sectioned at 20 micron thickness. All GAL tissues were sectioned in the transverse plane. $P O M C$ tissues were sectioned in either the transverse (1 male, 2 female) or sagittal plane (1 male, 1 female). 
Sections were thaw-mounted onto three replicate slide sets (Superfrost White, VWR, PA, USA) and dried at room temperature for two nights. Slides were stored at $-80{ }^{\circ} \mathrm{C}$ until processed for in situ hybridization.

\section{In situ hybridization}

To localize GAL, POMC1A, POMC1B, and POMC2-expressing cells in brain and pituitary tissue, chromogenic in situ hybridization of brain and pituitary tissue was performed as previously described [51]. RT-PCR was used to amplify target sequences from $A$. burtoni whole brain CDNA and introduce T3 RNA promoter sequences to the template. For antisense probe generation, the T3 RNA promoter sequence was introduced in the reverse primer. For sense probe generation, the T3 RNA promoter sequence was introduced in the forward primer. We identified a target region of low sequence identity $(\sim 40 \%)$ between the 3'UTRs of POMC1A ([GenBank : KC464872.1]) and POMC1B (Broad A. burtoni brain transcriptome [6], comp114_c0_seq1_indC_brain) mRNAs by sequence alignment using ClustalW (Geneious 8.0.5, Biomatters Inc.). The following primers were used to generate a template for cRNA antisense probe synthesis: GAL forward primer $5^{\prime}$-CTA GAT GGA CTA CAT GGA CAC AC-3', GAL reverse primer 5'-AAT TAA CCC TCA CTA AAC GGA TTG GCC AGT-3'; POMC1A forward primer 5' - GAG AAA AGA GGG AGG GAT GGA G-3', POMC1A reverse primer 5'-TGC AGT TGT GAA TA-3'; POMC1B forward primer 5'-AGA CGA GAA GAA GAT GAG GCA-3', $P O M C 1 B$ reverse primer $5^{\prime}$-GTC TAA TTG CCT TG3'; POMC2 forward primer 5'-GAC CTC TTA CTC AGC GTT ATT C-3', POMC2 reverse primer 5'-AGA TAG CAA CGA GTT TGT GTA A-3'.

\section{Additional files}

Additional file 1: Table S1. Location and accession numbers of identified A. burtoni prohormone and related genes. Genome scaffold locations and identities of supporting transcriptome data for all predicted A. burtoni prohormones and protein convertases. (CSV $27 \mathrm{~kb}$ )

Additional file 2: Text S1. Predicted A. burtoni prohormone and related sequences in FASTA format. All A. burtoni prohormone and protein convertase sequences and names as predicted by in silico search. (FA $44 \mathrm{~kb}$ )

Additional file 3: Table S2. Pituitary MALDI-TOF peptides confirmed by tandem MS. Sequences and masses peptides detected by both MALDI-TOF and tandem MS. (XLSX $11 \mathrm{~kb}$ )

Additional file 4: Table S3. A. burtoni pituitary peptides identified from tandem MS. Sequences and protein assignments of pituitary peptides detected by tandem MS. (CSV $87 \mathrm{~kb})$

Additional file 5: Figure S1. $P O M C 2$ expression throughout the $A$. burtoni brain. Representative in situ hybridization images of POMC2-expressing regions in the A. burtoni brain. (PDF $275 \mathrm{~kb}$ )

\section{Acknowledgements}

We thank the staff at Vincent Coates Foundation Mass Spectrometry Laboratory, Stanford University Mass Spectrometry, especially Christopher
Adams. We also thank Benjamin Lerman and Lisa Becker for their excellent technical assistance

\section{Funding}

This material is based upon work supported by a Gabilan Fellowship to CKH, Award No. P30 DA018310 from the National Institute on Drug Abuse to JVS and NIH Grants NS034950 and MH101373 to RDF. KPM was supported by startup funds from LSU College of Science. UPLC-ESI-IT MS described was supported by Award Number S1ORR027425 from the National Center For Research Resources. The content is solely the responsibility of the authors and does not necessarily represent the official views of the National Center For Research Resources or the National Institutes of Health.

\section{Availability of data and material}

The genomic dataset supporting the conclusions of this article is in the National Center for Biotechnology Information repository, GenBank assembly accession GCA_000239415.1, http://www.ncbi.nlm.nih.gov/assembly/322368.

The transcriptomic datasets supporting the conclusions of this article are also available in the National Center for Biotechnology Information repository, as well as Bouillabase.org (http://cichlid.umd.edu/cichlidlabs/kocherlab/ bouillabase.html). Mass spectrometry datasets are available upon request.

\section{Authors' contributions}

CKH contributed to MS sample preparation, ISH experiments, and bioinformatic analyses, and wrote the manuscript; BRS performed bioinformatic analyses and wrote the manuscript; EVR performed MS experiments and analysis and wrote the manuscript; KPM performed ISH experiments and analysis and wrote the manuscript; JVS and RDF contributed to experimental design, data analysis, and wrote the manuscript. All authors read and approved the final manuscript.

\section{Competing interests}

The authors declare that they have no competing interests.

\section{Consent for publication}

Not applicable.

\section{Ethics approvaland consent to participate}

All animal handling and treatment was in strict adherence to a protocol approved by Stanford University's Administrative Panel on Laboratory Animal Care (Protocol Number: 9882).

\section{Author details}

'Department of Biology, Stanford University, Stanford, CA 94305, USA. ${ }^{2}$ Department of Animal Sciences, University of Illinois at Urbana-Champaign, Urbana, IL 61801, USA. ${ }^{3}$ Department of Chemistry and the Beckman Institute, University of Illinois at Urbana-Champaign, Urbana, IL 61801, USA.

${ }^{4}$ Department of Biological Sciences, Louisiana State University, Baton Rouge, LA 70803, USA. ${ }^{5}$ resent address: Department of Organismic and

Evolutionary Biology, Harvard University, Cambridge, MA 02138, USA.

Received: 12 January 2016 Accepted: 6 July 2016

Published online: 19 August 2016

\section{References}

1. Kocher TD. Adaptive evolution and explosive speciation: the cichlid fish model. Nat Rev Genet. 2004;5:288-98.

2. Hoegg S, Boore JL, Kuehl JV, Meyer A. Comparative phylogenomic analyses of teleost fish Hox gene clusters: lessons from the cichlid fish Astatotilapia burtoni. BMC Genomics. 2007;8:317.

3. Bloomquist RF, Parnell NF, Phillips KA, Fowler TE, Yu TY, Sharpe PT, et al. Coevolutionary patterning of teeth and taste buds. Proc Natl Acad Sci U S A. 2015;112:E5954-62.

4. Albertson RC, Streelman JT, Kocher TD, Yelick PC. Integration and evolution of the cichlid mandible: the molecular basis of alternate feeding strategies. Proc Natl Acad Sci U S A. 2005:102:16287-92.

5. Fernald RD. Communication about social status. Curr Opin Neurobiol. 2014;28:1-4. 6. Brawand D, Wagner CE, Li YI, Malinsky M, Keller I, Fan S, et al. The genomic substrate for adaptive radiation in African cichlid fish. Nature. 2014;513:375-81.

7. Juntti SA, Hu CK, Fernald RD. To/2-Mediated generation of a transgenic haplochromine cichlid, Astatotilapia burtoni. PLoS One. 2013;8:e77647. 
8. Fujimura K, Kocher TD. Tol2-mediated transgenesis in tilapia (Oreochromis niloticus). Aquaculture. 2011;319:342-6.

9. Schartl M, Walter RB, Shen Y, Garcia T, Catchen J, Amores A, et al. The genome of the platyfish, Xiphophorus maculatus, provides insights into evolutionary adaptation and several complex traits. Nat Genet. 2013;45:567-72.

10. Glasauer SMK, Neuhauss SCF. Whole-genome duplication in teleost fishes and its evolutionary consequences. Mol Genet Genomics MGG. 2014;289:1045-60.

11. Brunet FG, Roest Crollius H, Paris M, Aury JM, Gibert P, Jaillon O, et al. Gene loss and evolutionary rates following whole-genome duplication in teleost fishes. Mol Biol Evol. 2006;23:1808-16.

12. He X, Zhang J. Rapid subfunctionalization accompanied by prolonged and substantial neofunctionalization in duplicate gene evolution. Genetics. 2005;169:1157-64.

13. Santos ME, Braasch I, Boileau N, Meyer BS, Sauteur L, Böhne A, et al. The evolution of cichlid fish egg-spots is linked with a cis-regulatory change. Nat Commun. 2014;5:5149.

14. Lang R, Gundlach AL, Holmes FE, Hobson SA, Wynick D, Hokfelt T, et al. Physiology, signaling, and pharmacology of galanin peptides and receptors: Three decades of emerging diversity. Pharmacol Rev. 2014;67:118-75.

15. Wu Z, Autry AE, Bergan JF, Watabe-Uchida M, Dulac CG. Galanin neurons in the medial preoptic area govern parental behaviour. Nature. 2014;509:325-30.

16. Mensah ET, Volkoff H, Unniappan S. Galanin systems in non-mammalian vertebrates with special focus on fishes. In: Hökfelt T, editor. Galanin, vol. 102. Basel: Springer Basel; 2010. p. 243-62.

17. Renn SCP, Aubin-Horth N, Hofmann HA. Fish and chips: functional genomics of social plasticity in an African cichlid fish. J Exp Biol. 2008;211:3041-56

18. Harris RM, Dijkstra PD, Hofmann HA. Complex structural and regulatory evolution of the pro-opiomelanocortin gene family. Gen Comp Endocrinol. 2014;195:107-15.

19. Ducrest A, Keller $L$, Roulin A. Pleiotropy in the melanocortin system, coloration and behavioural syndromes. Trends Ecol Evol. 2008;23:502-10.

20. Fernald RD, Hirata NR. Field study of Haplochromis burtoni: Quantitative behavioural observations. Anim Behav. 1977;25(Part 4):964-75.

21. Fernald RD. Social control of the brain. Annu Rev Neurosci. 2012;35:133-51.

22. Wagner CE, Harmon LJ, Seehausen O. Ecological opportunity and sexual selection together predict adaptive radiation. Nature. 2012;487:366-9.

23. Salzburger W, Mack T, Verheyen E, Meyer A. Out of Tanganyika: genesis, explosive speciation, key-innovations and phylogeography of the haplochromine cichlid fishes. BMC Evol Biol. 2005;5:17.

24. White SA, Nguyen T, Fernald RD. Social regulation of gonadotropinreleasing hormone. J Exp Biol. 2002;205:2567-81.

25. Greenwood AK, Wark AR, Fernald RD, Hofmann HA. Expression of arginine vasotocin in distinct preoptic regions is associated with dominant and subordinate behaviour in an African cichlid fish. Proc R Soc B Biol Sci. 2008; 275:2393-402

26. Okuyama $T$, Yokoi $S$, Abe $H$, Isoe $Y$, Suehiro $Y$, Imada $H$, et al. A neural mechanism underlying mating preferences for familiar individuals in medaka fish. Science. 2014;343:91-4.

27. Kim D-K, Cho EB, Moon MJ, Park S, Hwang J-I, Kah O, et al. Revisiting the evolution of gonadotropin-releasing hormones and their receptors in vertebrates: Secrets hidden in genomes. Gen Comp Endocrinol. 2011;170: 68-78.

28. Roch GJ, Busby ER, Sherwood NM. GnRH receptors and peptides: skating backward. Gen Comp Endocrinol. 2014;209:118-34.

29. Roch GJ, Busby ER, Sherwood NM. Evolution of GnRH: diving deeper. Gen Comp Endocrinol. 2011;171:1-16.

30. Valsalan R, Manoj N. Evolutionary history of the neuropeptide S receptor/ neuropeptide S system. Gen Comp Endocrinol. 2014;209:11-20.

31. Roch GJ, Tello JA, Sherwood NM. At the transition from invertebrates to vertebrates, a novel $\mathrm{GnRH}$-like peptide emerges in amphioxus. Mol Biol Evol. 2014;31:765-78.

32. Wang D-S, Jiao B, Hu C, Huang X, Liu Z, Cheng CHK. Discovery of a gonadspecific IGF subtype in teleost. Biochem Biophys Res Commun. 2008;367: 336-41.

33. Wilkinson TN, Speed TP, Tregear GW, Bathgate RAD. Evolution of the relaxin-like peptide family. BMC Evol Biol. 2005;5:14

34. Yegorov S, Good S. Using paleogenomics to study the evolution of gene families: origin and duplication history of the relaxin family hormones and their receptors. PLoS One. 2012;7:e32923.
35. Park CR, Moon MJ, Park S, Kim D-K, Cho EB, Millar RP, et al. A novel glucagon-related peptide (GCRP) and its receptor GCRPR account for coevolution of their family members in vertebrates. PLoS One. 2013:8:e65420

36. Wang Y, Meng F, Zhong Y, Huang G, Li J. Discovery of a novel glucagonlike peptide (GCGL) and its receptor (GCGLR) in chickens: evidence for the existence of GCGL and GCGLR genes in nonmammalian vertebrates. Endocrinology. 2012;153:5247-60.

37. Cardoso JCR, Félix RC, Trindade M, Power DM. Fish genomes provide novel insights into the evolution of vertebrate secretin receptors and their ligand. Gen Comp Endocrinol. 2014;209:82-92.

38. Tam JKV, Lee LTO, Jin J, Chow BKC. Molecular evolution of GPCRs: Secretin/ secretin receptors. J Mol Endocrinol. 2014;52:T1-14.

39. Tostivint $H$, Lihrmann I, Vaudry H. New insight into the molecular evolution of the somatostatin family. Mol Cell Endocrinol. 2008;286:5-17.

40. Tostivint H, Quan FB, Bougerol M, Kenigfest NB, Lihrmann I. Impact of gene/ genome duplications on the evolution of the urotensin II and somatostatin families. Gen Comp Endocrinol. 2013;188:110-7.

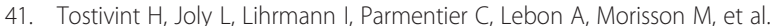
Comparative genomics provides evidence for close evolutionary relationships between the urotensin II and somatostatin gene families. Proc Natl Acad Sci U S A. 2006;103:2237-42.

42. Vaudry H, Do Rego J-C, Le Mevel J-C, Chatenet D, Tostivint H, Fournier A, et al. Urotensin II, from fish to human. Ann N Y Acad Sci. 2010;1200:53-66.

43. Conlon JM. "Liberation" of urotensin II from the teleost urophysis: an historical overview. Peptides. 2008;29:651-7.

44. Romanova EV, Sasaki K, Alexeeva V, Vilim FS, Jing J, Richmond TA, et al. Urotensin II in invertebrates: from structure to function in Aplysia californica. PLoS One. 2012;7:e48764.

45. Vanegas $\mathrm{G}$, Leprince J, Lancien F, Mimassi N, Vaudry H, Le Mével J-C. Divergent cardio-ventilatory and locomotor effects of centrally and peripherally administered urotensin II and urotensin I-related peptides in trout. Front Neurosci. 2015;9:142.

46. Leder $\mathrm{EH}$, Silverstein JT. The pro-opiomelanocortin genes in rainbow trout (Oncorhynchus mykiss): duplications, splice variants, and differential expression. J Endocrinol. 2006;188:355-63.

47. Sundström G, Dreborg S, Larhammar D. Concomitant duplications of opioid peptide and receptor genes before the origin of jawed vertebrates. PLoS One. 2010;5:e10512.

48. Dores RM, Baron AJ. Evolution of POMC: origin, phylogeny, posttranslational processing, and the melanocortins. Ann N Y Acad Sci. 2011;1220:34-48.

49. Southey BR, Rodriguez-Zas SL, Sweedler JV. Prediction of neuropeptide prohormone cleavages with application to RFamides. Peptides. 2006:27:1087-98.

50. Boorse GC, Crespi EJ, Dautzenberg FM, Denver RJ. Urocortins of the South African clawed frog, Xenopus laevis: conservation of structure and function in tetrapod evolution. Endocrinology. 2005;146:4851-60.

51. Grone BP, Maruska KP. A second corticotropin-releasing hormone gene $(\mathrm{CRH} 2)$ is conserved across vertebrate classes and expressed in the hindbrain of a basal Neopterygian fish, the spotted gar (Lepisosteus oculatus). J Comp Neurol. 2015;523:1125-43.

52. Grone BP, Maruska KP. Divergent evolution of two corticotropin-releasing hormone $(\mathrm{CRH})$ genes in teleost fishes. Front Neurosci. 2015;9:365.

53. Sakurai T. NPBWR1 and NPBWR2: Implications in energy homeostasis, pain, and emotion. Front Endocrinol. 2013:4:23.

54. Sundström G, Larsson TA, Brenner S, Venkatesh B, Larhammar D. Evolution of the neuropeptide $Y$ family: new genes by chromosome duplications in early vertebrates and in teleost fishes. Gen Comp Endocrinol. 2008:155:705-16

55. Conlon JM. The origin and evolution of peptide YY (PYY) and pancreatic polypeptide (PP). Peptides. 2002;23:269-78.

56. Larhammar D, Bergqvist CA. Ancient grandeur of the vertebrate neuropeptide $Y$ system shown by the coelacanth Latimeria chalumnae. Front Neurosci. 2013;7:27.

57. Pinheiro PLC, Cardoso JCR, Gomes AS, Fuentes J, Power DM, Canário AVM. Gene structure, transcripts and calciotropic effects of the PTH family of peptides in Xenopus and chicken. BMC Evol Biol. 2010;10:373.

58. Yan Y-L, Bhattacharya P, He XJ, Ponugoti B, Marquardt B, Layman J, et al. Duplicated zebrafish co-orthologs of parathyroid hormone-related peptide (PTHrP, Pthlh) play different roles in craniofacial skeletogenesis. J Endocrinol. 2012;214:421-35. 
59. Elphick MR, Mirabeau O. The evolution and variety of RFamide-type neuropeptides: Insights from deuterostomian invertebrates. Front Endocrinol. 2014;5:93.

60. Ukena K, Osugi T, Leprince J, Vaudry H, Tsutsui K. Molecular evolution of GPCRs: 26Rfa/GPR103. J Mol Endocrinol. 2014;52:T119-31.

61. Kim D-K, Yun S, Son GH, Hwang J-I, Park CR, Kim Jl, et al. Coevolution of the spexin/galanin/kisspeptin family: Spexin activates galanin receptor type II and III. Endocrinology. 2014;155:1864-73.

62. Yun S, Kim D-K, Furlong M, Hwang J-I, Vaudry H, Seong JY. Does kisspeptin belong to the proposed RF-amide peptide family? Front Endocrinol. 2014;5:134

63. Tena-Sempere M, Felip A, Gómez A, Zanuy S, Carrillo M. Comparative insights of the kisspeptin/kisspeptin receptor system: lessons from nonmammalian vertebrates. Gen Comp Endocrinol. 2012;175:234-43.

64. Osugi T, Ohtaki N, Sunakawa Y, Son YL, Ohkubo M, ligo M, et al. Molecular evolution of kiss2 genes and peptides in vertebrates. Endocrinology. 2013; 154:4270-80.

65. Unniappan S, Lin X, Peter RE. Characterization of complementary deoxyribonucleic acids encoding preprogalanin and its alternative splice variants in the goldfish. Mol Cell Endocrinol. 2003;200:177-87.

66. Kohchi C, Tsutsui K. Avian galanin: Cloning of complementary DNAs and characterization of transcripts in different tissues. J Exp Zool. 2000;287:183-90.

67. Southey BR, Rodriguez-Zas SL, Sweedler JV. Characterization of the prohormone complement in cattle using genomic libraries and cleavage prediction approaches. BMC Genomics. 2009;10:228.

68. Masso-Silva JA, Diamond G. Antimicrobial peptides from fish. Pharm Basel Switz. 2014;7:265-310

69. Xu Q, Cheng C-HC HP, Ye H, Chen Z, Cao L, et al. Adaptive evolution of hepcidin genes in antarctic notothenioid fishes. Mol Biol Evol. 2008;25:1099-112.

70. Inoue K, Naruse K, Yamagami S, Mitani H, Suzuki N, Takei Y. Four functionally distinct C-type natriuretic peptides found in fish reveal evolutionary history of the natriuretic peptide system. Proc Natl Acad Sci U S A. 2003:100:10079-84.

71. Murashita K, Kurokawa T. Multiple cocaine- and amphetamine-regulated transcript (CART) genes in medaka, Oryzias latipes: cloning, tissue distribution and effect of starvation. Gen Comp Endocrinol. 2011;170:494-500.

72. Akash G, Kaniganti T, Tiwari NK, Subhedar NK, Ghose A. Differential distribution and energy status-dependent regulation of the four CART neuropeptide genes in the zebrafish brain. J Comp Neurol. 2014:522:2266-85.

73. Bartolomucci A, Possenti R, Mahata SK, Fischer-Colbrie R, Loh YP, Salton SRJ. The extended granin family: structure, function, and biomedical implications. Endocr Rev. 2011;32:755-97.

74. Kudo H, Liu J, Jansen EJR, Ozawa A, Panula P, Martens GJM, et al. Identification of proSAAS homologs in lower vertebrates: conservation of hydrophobic helices and convertase-inhibiting sequences. Endocrinology. 2009;150:1393-9.

75. Shichiri M, Ishimaru S, Ota T, Nishikawa T, Isogai T, Hirata Y. Salusins: newly identified bioactive peptides with hemodynamic and mitogenic activities. Nat Med. 2003;9:1166-72.

76. Seidah NG, Sadr MS, Chrétien M, Mbikay M. The multifaceted proprotein convertases: their unique, redundant, complementary, and opposite functions. J Biol Chem. 2013;288:21473-81

77. Buchberger A, Yu Q, Li L. Advances in mass spectrometric tools for probing neuropeptides. Annu. Rev. Anal. Chem Palo Alto Calif. 2015;8:485-509.

78. Romanova EV, Sweedler JV. Peptidomics for the discovery and characterization of neuropeptides and hormones. Trends Pharmacol Sci. 2015;36:579-86

79. Romanova EV, Rubakhin SS, Ossyra JR, Zombeck JA, Nosek MR, Sweedler JV et al. Differential peptidomics assessment of strain and age differences in mice in response to acute cocaine administration. J Neurochem. 2015;135(5):1038-48

80. Fricker LD. Analysis of mouse brain peptides using mass spectrometrybased peptidomics: implications for novel functions ranging from nonclassical neuropeptides to microproteins. Mol Biosyst. 2010;6:1355-65.

81. Southey BR, Amare A, Zimmerman TA, Rodriguez-Zas SL, Sweedler JV. NeuroPred: a tool to predict cleavage sites in neuropeptide precursors and provide the masses of the resulting peptides. Nucleic Acids Res. 2006;34:W267-72.

82. Petersen TN, Brunak S, von Heijne G, Nielsen H. SignalP 4.0: discriminating signal peptides from transmembrane regions. Nat. Methods. 2011;8:785-6.

83. Kakuyama H, Kuwahara A, Mochizuki T, Hoshino M, Yanaihara N. Role of $\mathrm{N}$-terminal active sites of galanin in neurally evoked circular muscle contractions in the guinea-pig ileum. Eur J Pharmacol. 1997;329:85-91.
84. Schmidt WE, Kratzin H, Eckart K, Drevs D, Mundkowski G, Clemens A, et al. Isolation and primary structure of pituitary human galanin, a 30-residue nonamidated neuropeptide. Proc Natl Acad Sci. 1991;88:11435-9.

85. Martins RST, Pinto PIS, Guerreiro PM, Zanuy S, Carrillo M, Canário AVM. Novel galanin receptors in teleost fish: identification, expression and regulation by sex steroids. Gen Comp Endocrinol. 2014;205:109-20.

86. Gomes I, Dale CS, Casten K, Geigner MA, Gozzo FC, Ferro ES, et al. Hemoglobin-derived peptides as novel type of bioactive signaling molecules. AAPS J. 2010;12:658-69.

87. Gelman JS, Fricker LD. Hemopressin and other bioactive peptides from cytosolic proteins: are these non-classical neuropeptides? AAPS J. 2010;12:279-89.

88. Schelshorn DW, Schneider A, Kuschinsky W, Weber D, Krüger C, Dittgen T, et al. Expression of hemoglobin in rodent neurons. J. Cereb. Blood Flow Metab. Off. J. Int. Soc. Cereb. Blood Flow Metab. 2009;29:585-95.

89. Hatahet F, Ruddock LW. Protein disulfide isomerase: A critical evaluation of its function in disulfide bond formation. Antioxid Redox Signal. 2009:11:2807-50.

90. Yang Y, Li Z. Roles of heat shock protein gp96 in the ER quality control: redundant or unique function? Mol Cells. 2005;20:173-82.

91. Malacombe M, Bader M-F, Gasman S. Exocytosis in neuroendocrine cells: New tasks for actin. Biochim Biophys Acta. 2006;1763:1175-83.

92. Wang W-A, Groenendyk J, Michalak M. Calreticulin signaling in health and disease. Int J Biochem Cell Biol. 2012:44:842-6.

93. Magliulo-Cepriano L, Schreibman MP, Blüm V. The distribution of immunoreactive FMRF-amide, neurotensin, and galanin in the brain and pituitary gland of three species of Xiphophorus from birth to sexual maturity. Gen Comp Endocrinol. 1993;92:269-80.

94. Jadhao A, Pinelli C. Galanin-like immunoreactivity in the brain and pituitary of the "four-eyed" fish, Anableps anableps. Cell Tissue Res. 2001;306:309-18.

95. Burmeister SS, Munshi RG, Fernald RD. Cytoarchitecture of a cichlid fish telencephalon. Brain Behav Evol. 2009;74:110-20.

96. Cerda-Reverter JM, Zanuy S, Munoz-Cueto JA. Cytoarchitectonic study of the brain of a perciform species, the sea bass (Dicentrarchus labrax). II. The diencephalon. J Morphol. 2001;247:229-51.

97. Batten TFC, Moons L, Cambre M, Vandesande F. Anatomical distribution of galanin-like immunoreactivity in the brain and pituitary of teleost fishes. Neurosci Lett. 1990;111:12-7.

98. Fryer JN, Boudreault-Chateauvert C, Kirby RP. Pituitary afferents originating in the paraventricular organ (PVO) of the goldfish hypothalamus. J Comp Neurol. 1985;242:475-84.

99. Olivereau M, Olivereau JM. Immunocytochemical localization of a galaninlike peptidergic system in the brain of two urodele and two anuran species (Amphibia). Histochemistry. 1992;98:51-66.

100. Unniappan S, Cerdá-Reverter JM, Peter RE. In situ localization of preprogalanin mRNA in the goldfish brain and changes in its expression during feeding and starvation. Gen Comp Endocrinol. 2004;136:200-7.

101. Olivereau M, Olivereau JM. Immunocytochemical localization of a galaninlike peptidergic system in the brain and pituitary of some teleost fish. Histochemistry. 1991:96:343-54.

102. Yamamoto T, Maler L, Nagy Jl. Organization of galanin-like immunoreactive neuronal systems in weakly electric fish (Apteronotus leptorhynchus). J Chem Neuroanat. 1992;5:19-38.

103. Anglade I, Wang Y, Jensen J, Tramu G, Kah O, Conlon JM. Characterization of trout galanin and its distribution in trout brain and pituitary. J Comp Neurol. 1994:350:63-74.

104. Takahashi A, Amano M, Amiya N, Yamanome T, Yamamori K, Kawauchi H. Expression of three proopiomelanocortin subtype genes and mass spectrometric identification of POMC-derived peptides in pars distalis and pars intermedia of barfin flounder pituitary. Gen Comp Endocrinol. 2006;145:280-6.

105. de Souza FSJ, Bumaschny VF, Low MJ, Rubinstein M. Subfunctionalization of expression and peptide domains following the ancient duplication of the proopiomelanocortin gene in teleost fishes. Mol Biol Evol. 2005;22:2417-27.

106. Khan FA, Saha SG, Sarkar S, Subhedar N. Beta-endorphin-like immunoreactivity in the forebrain and pituitary of the teleost Clarias batrachus (Linn.). Gen. Comp. Endocrinol. 1999;113:290-301.

107. Vallarino M. Occurrence of beta-endorphin-like immunoreactivity in the brain of the teleost, Boops boops. Gen Comp Endocrinol. 1985;60:63-9.

108. Delfino KR, Southey BR, Sweedler JV, Rodriguez-Zas SL. Genome-wide census and expression profiling of chicken neuropeptide and prohormone convertase genes. Neuropeptides. 2010;44:31-44. 
109. Xie F, London SE, Southey BR, Annangudi SP, Amare A, Rodriguez-Zas SL, et al. The zebra finch neuropeptidome: prediction, detection and expression. BMC Biol. 2010;8:28.

110. Birney E, Clamp M, Durbin R. GeneWise and Genomewise. Genome Res. 2004;14:988-95.

111. Fernald RD. Quantitative behavioural observations of Haplochromis burtoni under semi-natural conditions. Anim Behav. 1977;25(Part 3):643-53.

112. Zhang J, Xin L, Shan B, Chen W, Xie M, Yuen D, et al. PEAKS DB: de novo sequencing assisted database search for sensitive and accurate peptide identification. Mol Cell Proteomics MCP. 2012;11:M111.010587.

113. Baldwin GS, Patel O, Shulkes A. Phylogenetic analysis of the sequences of gastrin-releasing peptide and its receptors: biological implications. Regul Pept. 2007;143:1-14.

114. Ogoshi M, Inoue K, Naruse K, Takei Y. Evolutionary history of the calcitonin gene-related peptide family in vertebrates revealed by comparative genomic analyses. Peptides. 2006;27:3154-64.

115. Chang CL, Hsu SYT. Ancient evolution of stress-regulating peptides in vertebrates. Peptides. 2004;25:1681-8.

116. Bräutigam L, Hillmer JM, Söll I, Hauptmann G. Localized expression of urocortin genes in the developing zebrafish brain. J Comp Neurol. 2010:518:2978-95

117. Lovejoy DA. Structural evolution of urotensin-l: reflections of life before corticotropin releasing factor. Gen Comp Endocrinol. 2009;164:15-9.

118. Braasch I, Volff J-N, Schartl M. The endothelin system: evolution of vertebrate-specific ligand-receptor interactions by three rounds of genome duplication. Mol Biol Evol. 2009;26:783-99.

119. Murashita K, Kurokawa T, Nilsen TO, Rønnestad I. Ghrelin, cholecystokinin, and peptide YY in Atlantic salmon (Salmo salar): molecular cloning and tissue expression. Gen Comp Endocrinol. 2009;160:223-35.

120. Liu Y, Li S, Huang X, Lu D, Liu X, Ko W, et al. Identification and characterization of a motilin-like peptide and its receptor in teleost. Gen Comp Endocrinol. 2013;186:85-93.

121. Roch GJ, Wu S, Sherwood NM. Hormones and receptors in fish: do duplicates matter? Gen Comp Endocrinol. 2009;161:3-12.

122. Tostivint $\mathrm{H}$. Evolution of the gonadotropin-releasing hormone $(\mathrm{GnRH})$ gene family in relation to vertebrate tetraploidizations. Gen Comp Endocrinol. 2011;170:575-81.

123. Lindemans $M$, Janssen T, Beets I, Temmerman L, Meelkop E, Schoofs L. Gonadotropin-releasing hormone and adipokinetic hormone signaling systems share a common evolutionary origin. Front Endocrinol. 2011;2:16.

124. Sefideh FA, Moon MJ, Yun S, Hong SI, Hwang J-I, Seong JY. Local duplication of gonadotropin-releasing hormone $(\mathrm{G} n \mathrm{RH})$ receptor before two rounds of whole genome duplication and origin of the mammalian GnRH receptor. PLoS One. 2014;9:e87901.

125. Zhao E, Zhang D, Basak A, Trudeau VL. New insights into granin-derived peptides: evolution and endocrine roles. Gen Comp Endocrinol. 2009;164:161-74.

126. Montero-Hadjadje M, Vaingankar S, Elias S, Tostivint H, Mahata SK, Anouar Y. Chromogranins A and B and secretogranin II: evolutionary and functional aspects. Acta Physiol Oxf Engl. 2008;192:309-24.

127. Caruso MA, Sheridan MA. New insights into the signaling system and function of insulin in fish. Gen Comp Endocrinol. 2011;173:227-47.

128. Mechaly AS, Viñas J, Piferrer F. The kisspeptin system genes in teleost fish, their structure and regulation, with particular attention to the situation in Pleuronectiformes. Gen Comp Endocrinol. 2013;188:258-68.

129. Ogawa S, Parhar IS. Anatomy of the kisspeptin systems in teleosts. Gen Comp Endocrinol. 2013;181:169-74.

130. Mensah ET, Volkoff H, Unniappan S. Galanin systems in non-mammalian vertebrates with special focus on fishes. EXS. 2010;102:243-62.

131. Kang D-Y, Kim H-C. Functional characterization of two melaninconcentrating hormone genes in the color camouflage, hypermelanosis, and appetite of starry flounder. Gen Comp Endocrinol. 2013;189:74-83.

132. Kono $T$, Hamasuna $S$, Korenaga $H$, lizasa $T$, Nagamine $R$, Ida $T$, et al. The role of neuromedin $U$ during inflammatory response in the common carp. Fish Shellfish Immunol. 2012:32:151-60.

133. Takahashi A, Kawauchi H. Evolution of melanocortin systems in fish. Gen Comp Endocrinol. 2006;148:85-94.

134. Komorowski LK, Lecaude SG, Westring CG, Danielson PB, Dores RM. Evolution of gnathostome prodynorphin and proenkephalin: characterization of a shark proenkephalin and prodynorphin cDNAs. Gen Comp Endocrinol. 2012;177:353-64.
135. Roberts E, Shoureshi P, Kozak K, Szynskie L, Baron A, Lecaude S, et al. Tracking the evolution of the proenkephalin gene in tetrapods. Gen Comp Endocrinol. 2007;153:189-97.

136. Wong KKY, Ng SYL, Lee LTO, Ng HKH, Chow BKC. Orexins and their receptors from fish to mammals: a comparative approach. Gen Comp Endocrinol. 2011:171:124-30.

137. Gwee P-C, Amemiya CT, Brenner S, Venkatesh B. Sequence and organization of coelacanth neurohypophysial hormone genes: evolutionary history of the vertebrate neurohypophysial hormone gene locus. BMC Evol Biol. 2008:8:93.

138. Canario AVM, Rotllant J, Fuentes J, Guerreiro PM, Rita Teodósio H, Power DM, et al. Novel bioactive parathyroid hormone and related peptides in teleost fish. FEBS Lett. 2006;580:291-9.

139. Guerreiro PM, Renfro JL, Power DM, Canario AVM. The parathyroid hormone family of peptides: structure, tissue distribution, regulation, and potentia functional roles in calcium and phosphate balance in fish. Am J Physiol Regul Integr Comp Physiol. 2007;292:R679-96.

140. Good-Avila SV, Yegorov S, Harron S, Bogerd J, Glen P, Ozon J, et al. Relaxin gene family in teleosts: phylogeny, syntenic mapping, selective constraint, and expression analysis. BMC Evol Biol. 2009;9:293.

141. Liu Y, Zhang Y, Li S, Huang W, Liu X, Lu D, et al. Molecular cloning and functional characterization of the first non-mammalian 26RFa/QRFP orthologue in Goldfish, Carassius auratus. Mol Cell Endocrinol. 2009:303:82-90.

142. Zhang Y, Li S, Liu Y, Lu D, Chen H, Huang X, et al. Structural diversity of the $\mathrm{GnlH/GnlH}$ receptor system in teleost: its involvement in early development and the negative control of LH release. Peptides. 2010;31:1034-43.

143. Sakamoto T, Oda A, Narita K, Takahashi H, Oda T, Fujiwara J, et al. Prolactin: fishy tales of its primary regulator and function. Ann N Y Acad Sci. 2005;1040:184-8.

144. Zhou W, Li S, Liu Y, Qi X, Chen H, Cheng CHK, et al. The evolution of tachykinin/tachykinin receptor (TAC/TACR) in vertebrates and molecular identification of the TAC3/TACR3 system in zebrafish (Danio rerio). Mol Cell Endocrinol. 2012;361:202-12.

145. Wallis M. Molecular evolution of the thyrotrophin-releasing hormone precursor in vertebrates: insights from comparative genomics. Neuroendocrinol. 2010;22:608-19.

\section{Submit your next manuscript to BioMed Central and we will help you at every step:}

- We accept pre-submission inquiries

- Our selector tool helps you to find the most relevant journal

- We provide round the clock customer support

- Convenient online submission

- Thorough peer review

- Inclusion in PubMed and all major indexing services

- Maximum visibility for your research

Submit your manuscript at www.biomedcentral.com/submit 